NASA Technical Memorandum 106545

AIAA-94-2590

\title{
Flow Quality Studies of the NASA Lewis Research Center Icing Research Tunnel
}

E. Allen Arrington

NYMA, Inc.

Engineering Services Division

Brook Park, Ohio

and

Mark T. Pickett and David W. Sheldon

National Aeronautics and Space Administration

Lewis Research Center

Cleveland, Ohio

Prepared for the

18th Aerospace Ground Testing Conference

sponsored by the American Institute of Aeronautics and Astronautics

Colorado Springs, Colorado, June 20-23, 1994 


\title{
FLOW QUALITY STUDIES OF THE NASA LEWIS RESEARCH CENTER
}

\section{ICING RESEARCH TUNNEL}

\author{
E. Allen Arrington \\ NYMA, Inc. \\ Engineering Services Division \\ Brook Park, Ohio 44142 \\ Mark T. Pickett and David W. Sheldon \\ National Aeronautics and Space Administration \\ Lewis Research Center \\ Cleveland, Ohio 44135
}

\begin{abstract}
$\underline{\text { Abstract }}$
A series of studies have been conducted to determine the flow quality in the NASA Lewis Icing Research Tunnel. The primary purpose of these studies was to document airflow characteristics, including flow angularity, in the test section and tunnel loop. A vertically mounted rake was used to survey total and static pressure and two components of flow angle at three axial stations within the test section (test section inlet, test plane, and test section exit; 15 survey stations total). This information will be used to develop methods of improving the aerodynamic and icing characteristics within the test section. The data from surveys made in the tunnel loop were used to determine areas where overall tunnel flow quality and efficiency can be improved. A separate report documents similar flow quality surveys conducted in the diffuser section of the Icing Research Tunnel. ${ }^{1}$
\end{abstract}

The flow quality studies were conducted at several locations around the tunnel loop. Pressure, velocity, and flow angularity measurements were made by using both fixed and translating probes. Although surveys were made throughout the tunnel loop, emphasis was placed on the test section and tunnel areas directly upstream of the test section (settling chamber, bellmouth, and cooler). Flow visualization, by video recording smoke and tuft patterns, was also used during these studies. A great deal of flow visualization work was conducted in the area of the drive fan. Information gathered there will be used to improve the flow quality upstream and downstream of the fan.

\section{Introduction}

Flow field surveys were made in the test section and tunnel loop components as part of a program to improve the flow quality in the NASA Lewis Research Center Icing Research Tunnel (IRT). These studies mapped the flow quality in the test section and through the tunnel loop. The goal of

\footnotetext{
* Since these flow quality studies were completed, the facility drive fan was modified such that the maximum empty test section speed is about $400 \mathrm{mph}$.
}

this program was is to improve the aerodynamic characteristics (Mach number and flow angularity distributions) in the test section. Surveys of total and static pressure and flow angularity were made by using 11 five-hole hemisphericalhead flow angularity probes mounted on a vertically oriented rake. This rake was used to map the flow at three axial stations in the test section (five rake positions at each axial station survey plane).

While the primary mission of the IRT is that of an icing wind tunnel, some aerodynamic testing is performed in the facility. Only aerodynamic data were collected during the flow quality studies. Although these data will be used to develop improvements to both the aerodynamic and icing capabilities of the wind tunnel, only the aerodynamic aspects are addressed in this report.

The primary objective of this work is to report the data and describe the measurements made, instrumentation used, and results obtained in support of the flow quality studies.

\section{Description of Facility}

The NASA Lewis Research Center's Icing Research Tunnel is a closed-loop atmospheric tunnel with rectangular cross sections. The airflow is driven by a 25 - $\mathrm{ft}$ diameter, $12-$ blade fan that is powered by a $5000-\mathrm{hp}$ electric motor. The tunnel test section is $6 \mathrm{ft}$ high, $9 \mathrm{ft}$ wide, and $20 \mathrm{ft}$ long. The velocity in the empty test section varies from 50 to $300 \mathrm{mph}^{*}$ (Mach range of 0.065 to 0.40 ) at $0^{\circ} \mathrm{F}$. Figure 1 shows a schematic of the tunnel. A 2100-ton cooler (heat exchanger) located in the tunnel leg between Corners $C$ and $D$ is used to control the tunnel air temperature. Eight horizontal spray bars, located upstream of the test section, inject atomized water into the airflow to create icing conditions. No icing conditions were studied in these tests. Reference 2 gives a complete description of the facility. The test locations for this study are shown in Fig. 1 also. 
Instrumentation and Test Hardware

Flow Field Surveys

Test section survey rake. A 6-ft, vertically oriented rake, instrumented with 11 five-hole hemispherical-head flow angularity probes spaced at 6-in. intervals, was used to survey the flow field in the test section. Figure 2 shows the rake installed in the test section and describes the instrumentation layout on the rake. The rake structure comprises four 1-in. channel sections rivetted in pairs to form I-beams. These Ibeams were tied together by aluminum plates to form the main structure (Fig. 2(c)). Aerodynamic fairings were added to the leading and trailing edges of the rake. The probe supports were mounted through the leading edge fairing and main rake beams; the instrumentation lines were enclosed by the trailing edge fairing.

Flow angularity probes. Eleven five-hole hemispherical-head flow angularity probes were mounted to the survey rake as described in the preceding paragraph. Figure 3 shows a typical five-hole hemispherical-head probe used in this program. This type of probe is capable of sensing two components of flow angle as well as total and static pressure. The linear range of the probe for flow angle measurements is generally $\pm 20^{\circ}$. These probes were calibrated for flow angles of $\pm 20^{\circ}$ and for Mach numbers of between 0.2 and 0.45 . The probes were not calibrated specifically for use in the IRT but were calibrated over a different Mach number range for a flow quality test in another facility; therefore, the calibration range does not exactly match the Mach number range of the IRT. The five probes on the lower portion of the rake were calibrated at Mach numbers of $0.2,0.25$, and 0.3 ; the next five higher probes, at Mach 0.35, 0.4, and 0.45; and the topmost probe was uncalibrated. (The calibration data from another probe was used for this probe.) This method will decrease the accuracy of the flow angularity measurements made with these probes. Accuracy is approximately $\pm 0.3^{\circ}$ based on the probe calibration, rake alignment, and measurement system.

Boundary layer rake. Boundary layer total pressure measurements were made in the test section using the rake shown in Fig. 4. Eighteen pressure probes were mounted on the rake; however, the probes nearest the end of the rake (16, 17 , and 18 ) were inoperative during the tests.

Wind anemometers. Two types of wind anemometers were used in the study. A hand-held model was used to determine the velocity distribution in Corners $\mathrm{B}, \mathrm{C}$, and $\mathrm{D}$ (Fig. 1) and in the settling chamber (airspeed only), and a vane-type anemometer was used both upstream and downstream of the cooler and in the settling chamber to determine airspeed and pitch and yaw flow angles. Both types of anemometers are shown in Fig. 5. The hand-held model has an accuracy of 0.5 percent of the instrument reading. The vanetype anemometer accuracy is $\pm 3.28 \mathrm{ft} / \mathrm{sec}$ for airspeed, $\pm 0.35^{\circ}$ in pitch, and $\pm 0.25^{\circ}$ in yaw.
Traversing plates. A traversing plate mechanism was used to obtain velocity and flow angularity distribution data across large sections of the tunnel. The apparatus consisted of a flat plate supported by cables at the leading and trailing edges. The cables were attached to channels mounted to the tunnel floor and ceiling. The leading edge cable rode on a pulley and was driven by a remotely controlled electric motor so that the plate could be positioned at any point across the survey plane. This setup was used for floor-to-ceiling surveys both upstream and downstream of the cooler and in Corner D (settling chamber). Figure 6 shows this apparatus installed in Corner D (survey plane 7 in Fig. 1). The instrumentation mounted to the plate during these surveys consisted of one vane-type anemometer. The accuracy of the flow angularity measured by the instrumentation mounted on the traversing plates could be affected by deflection of the plate caused by aerodynamic loading. This could produce an offset of a couple of degrees in the measured flow angularity data, but no attempts were made to quantify this offset.

Data system. The standard tunnel data system was used to record the pressure measurements made during the test section survey portion of the study. The tunnel data system consists of a VAX-based data acquisition system used in conjunction with an electrically scanned pressure system (ESP). For these tests, 5-psid ESP modules were used so that the accuracy of the pressure measurements was \pm 0.0035 psia.

\section{Flow Visualization}

Both tufts and smoke were used to determine the flow quality in several tunnel loop areas. Tufts were tied to horizontal wires upstream of the turning vanes in Corner $\mathrm{C}$ (Fig. 7). These tufts were used to determine the flow distribution entering this corner. Smoke generators were used upstream and downstream of the fan and in the settling chamber upstream of the test section. The smoke generators were small electrically ignited canisters that produced $100,000 \mathrm{ft}^{3}$ of smoke over a 5 -min period. The canisters were mounted to the tunnel structure and on a long pole to allow movement of the smoke source throughout the test area. A hand-held video camera was used to record the motion of the tufts and smoke traces during all flow visualization tests.

\section{Test Procedures}

\section{Test Section Surveys}

Figure 8 shows the layout of the IRT test section with the three axial survey station test planes: test section inlet (positioned at -2 percent of test section length), test plane (42 percent), and test section exit ( 72 percent). There were five rake positions at each axial station, (totalling 15 rake positions). Before each tunnel run, the rake was aligned parallel to the test section centerline. The flow field was then surveyed using this rake configuration for test section velocities from 50 to $300 \mathrm{mph}$ in 25 - $\mathrm{mph}$ increments. Following the completion of the sweep, the rake configuration was changed and the 
survey procedure repeated. In this manner, the entire test section flow field was surveyed.

\section{Tunnel Loop Surveys}

Traversing plate/vane anemometer surveys were automated so that all hardware operation and data recording was controlled from the facility control room. Because only one traversing unit was available, several test runs were required to complete all surveys. Data were collected at conditions corresponding to test section velocities of 100,200 , and $300 \mathrm{mph}$, although other settings were used at times. The intent was to map the flow throughout the tunnel loop which corresponded to these velocity conditions, but operational constraints prevented collection of all data in some locations.

Surveys using the hand-held anemometer were conducted at several locations around the tunnel loop (Fig. 1) by a two-man team; one member of the team operated the anemometer while the second member recorded the data. These surveys were conducted at conditions corresponding to test section velocities of 100,200 , and $300 \mathrm{mph}$. The handheld anemometer was used to provide a fast and efficient means of measuring the velocity at several areas around the tunnel loop. The measurements made using this instrumentation could be affected by the presence of the survey team.

\section{Discussion of Results}

\section{Flow Quality Goals}

Flow quality goals for the NASA Lewis wind tunnels have been defined and are listed in Table 1. These goals are based on information and recommendations from the Wind Tunnel Calibration Workshop held at NASA Langley ${ }^{3}$ and modified for the specific missions of the propulsion wind tunnel facilities at NASA Lewis. For the IRT, these goals have been modified for the specific requirements of an icing tunnel. The IRT flow quality goals are also presented in Table 1.

\section{Test Section Surveys}

The primary goal of these studies was to determine flow quality and document flow parameters at several locations in the test section of the IRT. A large amount of data on the test section flow quality was collected during the program; a large portion of the data over the operating range of the facility are included in this report. The total and static pressure and Mach number data have been normalized by the corresponding freestream conditions as measured by the facility test section rake to eliminate variations between runs. These data are summarized as surface plots. The pitch and yaw flow angle data have been used to construct directional vectors at each probe position (the direction of the vector indicates the flow direction; the length of the vector indicates the magnitude of the component pitch and yaw data). These data plots are contained in the appendix (Figs. 21 to 40). The average test conditions in the test section during the surveys are listed in Table 2.

For each rake position, the vertical Mach number distribution provides an acceptable variation of less than 0.005 over most of the survey line. (In some cases, the probes nearest the floor and ceiling exceed the 0.005 criterion, probably as a result of boundary layer effects.) Figure 9 presents examples of measured Mach number data showing this variation. (These are typical results for most of the data.) When the data from the five rake axial positions at an axial station are used to construct the surface plot, there are some instances in which the variation in Mach number is larger than 0.005 across the test section, but does not exceed 0.015 . Based on the Mach number variation over the survey plane, the flow quality in the test section meets the 0.005 Mach number variation goal in the area where the test articles would be positioned. However, there are some areas within the surveyed area that do not meet the 0.005 goal. A total pressure deficit apparent at the floor and ceiling of the centerline survey position causes a Mach number deficit of 0.010 to 0.015 and is more pronounced near the test section ceiling. At present, the cause of this total pressure deficit is not known. Since it occurs near the boundaries of the test section, it does not have an effect on the Mach number distribution used for most aerodynamic tests. ${ }^{* *}$ Table 3 summarizes the variations in total and static pressure and Mach number over the test section axial survey station 2 (turntable centerline); these results exclude data from the probe on either end of the survey rake.

The flow angularity data are presented in a vector format in the appendix. As mentioned, these probes were not calibrated specifically for the test conditions used in these studies. Although this will affect the overall accuracy of the data, the flow angularity trends are correct. For this reason, the data are considered preliminary. Data show a significant amount of motion in the flow paths, indicating a general trend in the pitch angle of flow toward the center of the test section (downward flow at the upper portion of the test section and upward flow in the lower portion). The significant variation in the yaw flow angle component could indicate swirl in the flow or be due to disturbances caused by the tunnel cooler and/or by the spray bar system.

The boundary layer measurements are presented in Fig. 10. These measurements were made on centerline of the test section floor at test section axial survey station 2 (test section station 101). At speeds of $200 \mathrm{mph}$ and higher, the boundary layer thickness is approximately $4 \mathrm{in}$.

\footnotetext{
** This total pressure distortion does not seem to adversely affect the size of the icing cloud as seen in previous icing cloud calibrations. However, discussion of the icing performance of the tunnel is beyond the scope of this report.
} 


\section{Tunnel Loop Surveys}

Figure 11 shows the velocity distribution along the survey plane in Corner B (survey plane 1). These surveys were made by using the hand-held anemometer at conditions corresponding to a test section velocity of $100 \mathrm{mph}$. The survey was made downstream of the turning vanes in a plane parallel to the drive fan; data were taken at 41 and 125 in. above the tunnel floor. (Tunnel dimensions at this position are $19 \mathrm{ft}$ wide by $16 \mathrm{ft}$ high.) Higher velocities were recorded along the 125 -in. survey height (maximum velocity of $40 \mathrm{ft} / \mathrm{sec}$ compared with $33 \mathrm{ft} / \mathrm{sec}$ at the 41 -in. survey height), but there were also indications of a larger velocity gradient near the inside tunnel wall. The velocity distribution at the 41 -in. survey height was much flatter. Neglecting the measurements made at the tunnel walls, the variation in velocity at the 41 -in. survey height is 22 percent, whereas at the 125 -in. survey height, the variation is 46 percent.

Velocity measurements using the hand-held anemometer were also made downstream of the drive fan near the aft end of the drive motor housing (survey plane 2). Data were collected at a test section velocity of $200 \mathrm{mph}$. The airspeed on either side of the drive motor housing was approximately equal $(32.8 \mathrm{ft} / \mathrm{sec}$ on the north side of the housing compared with $31.7 \mathrm{ft} / \mathrm{sec}$ on the south side), but much higher velocities were recorded under the housing $(64.4 \mathrm{ft} / \mathrm{sec})$. The higher velocities were the result of the reduced area under the housing where a duct is formed by the drive housing supports.

Figure 12 shows the velocity distributions measured by using the hand-held anemometer along the survey plane in Corner C (survey plane 3 ). The measurements were made along the leading edge of the turning vanes in Corner $\mathrm{C}$. At this station, data were collected corresponding to test section velocities of 100,200, and $300 \mathrm{mph}$. The effect of the splitter wall on the flow field was of primary interest in this area. The splitter wall separates the large main cooler from the smaller air cooler downstream of Corner C (Fig. 1). For all test conditions, higher velocities were recorded along the inside of the tunnel loop. The maximum velocity was recorded at approximately $10 \mathrm{ft}$ from the inside wall. At about $25 \mathrm{ft}$ from the inside wall, the velocity began to decreased and continued to decrease across the remainder of the survey plane, a length of $41.25 \mathrm{ft}$.

Both vertical and horizontal surveys were made at survey plane 4, which is located upstream of the air cooler. There are two coolers in the tunnel loop: the larger is located to the outside of the splitter wall and is shaped like a sideways "W" (see Fig. 13); the smaller is located to the inside of the splitter wall and is shaped like a "double W." The traversing plate and vane anemometer were used to obtain velocity and flow angularity data along a vertical survey plane at test section velocities of 200,250 , and $310 \mathrm{mph}$. The vertical survey plane was located just upstream of the cooler and $9.5 \mathrm{ft}$ from the outside tunnel wall. Figure 14 shows the data from the vertical surveys. In each case, a velocity gradient was present with higher velocities recorded near the tunnel floor (within 4 to $8 \mathrm{ft}$ of the floor and steadily decreasing toward the ceiling). A vertical trend was also seen in the pitch flow angle data (Fig. 14(b)). For all cases, an upflow (positive pitch angle) was measured along the lower half to two-thirds of the survey plane. Downflow (negative pitch angle) was measured along the upper portion of the survey plane, although positive angles were measured near the ceiling of the tunnel for the test section velocity equals $310 \mathrm{mph}$ case $\left(\mathrm{V}_{\mathrm{TS}}=310 \mathrm{mph}\right)$. Yaw angles measured along this survey plane indicate small flow angles along the lower two-thirds of the survey (yaw angles were between $\pm 3^{\circ}$; outflow-flow toward the outside tunnel wall-is denoted by positive yaw angles) with larger flow angles and more scatter recorded along the upper third of the survey (Fig. 14(c)).

The hand-held anemometer was used along a horizontal plane 89-in. from the tunnel floor at the leading edge of the cooler inlet. These data were collected at a test section velocity of $100 \mathrm{mph}$. Figure 15 shows the velocity distribution across this survey plane. The data show that a uniform velocity distribution entering the main cooler along this horizontal plane.

Vertical and horizontal surveys were also made downstream of the cooler (survey plane 5). The traversing plate and vane anemometer were used to provide velocity and flow angularity data along a vertical survey plane at test section velocities of 200,250 , and $310 \mathrm{mph}$. The vertical survey plane was located $2.2 \mathrm{ft}$ downstream of the cooler and $9.5 \mathrm{ft}$ from the outside tunnel wall (the same distance from the outside wall as the surveys made upstream of the cooler, survey plane 4). The data from the vertical surveys are shown in Fig. 16. It can be seen that the velocity and pitch flow angle were affected by the presence of the cooler. The two large velocity deficit regions at vertical positions of 7 and $14 \mathrm{ft}$ above the floor correspond to the bends in the cooler (at 7 and $13 \mathrm{ft}$ above the tunnel floor). There is a small discontinuity at $20 \mathrm{ft}$ above the floor that roughly matches the height of the remaining cooler bend, which is $19 \mathrm{ft}$ above the floor. Most of the flow disturbance appears to be caused by the cooler bend at $13 \mathrm{ft}$ above the tunnel floor at the cooler inlet. The fairing at this bend forces the flow away from the center of the tunnel; the turning vanes on the cooler (Fig. 11) do not correctly redistribute the flow to eliminate the deficit region. The pitch flow angularity data shows that the flow basically follows the contour of the cooler; the flow is directed downward along the portion of the survey below the inlet bend fairing and directed upward for the portion of the survey above the inlet bend fairing. Yaw flow angle data also indicate flow disturbances caused by the bends in the cooler. The yaw angle is generally around $0^{\circ}$ to $1^{\circ}$ except at 7,14 , and $20 \mathrm{ft}$ above the tunnel floor where spikes appear in the data. The spikes that occur at these heights are produced by the fairings at the cooler bends.

Horizontal velocity surveys taken with the hand-held anemometer show uniform distributions across the cross sec- 
tion of the tunnel at three heights and at a test section velocity of $100 \mathrm{mph}$ (Fig. 17).

The velocity distributions along survey plane 6 (along Corner D turning vanes) are shown in Fig. 18. The height of the survey was $9.7 \mathrm{ft}$ (116.4 in.) above the tunnel floor. Data were collected with the tunnel vent doors open and closed in order to see the effects on the flow through the main and secondary (inner) cooler. Velocity distributions with the doors open or closed varies only slightly except in the area of the splitter wall. Operating the facility with the vent doors closed (normal operating mode) provides a more even velocity distribution over the survey plane. The effect of the vent doors is less apparent at lower test section velocities. The higher velocities measured at $25 \mathrm{ft}$ from the south (outside) wall to the splitter wall may be due to a reduced area at the point because of the presence of horizontal fairings (cooler protrusions through Corner $\mathrm{D}$ turning vanes).

Data from the vertical vane anemometer survey in the settling chamber (survey plane 7) are presented in Fig. 19. The survey plane is located downstream of the Corner D turning vanes, upstream of the spray bars, and is parallel with the test section inlet. The velocity data indicate that the deficit region caused by blockage at the cooler inlet (the cooler inlet bend fairing positioned $13 \mathrm{ft}$ from the tunnel floor, Fig. 11) is still present. The effect of the cooler on the pitch flow angle data has dissipated through Corner $\mathrm{D}$. The pitch angle is generally between $0^{\circ}$ and $2^{\circ}$ (upflow), although larger negative (downflow) measurements were recorded near the floor and ceiling of the tunnel. The yaw flow angle was consistently negative over the survey plane, which indicates flow toward the north wall (from south to north). This could be due to overturning of the flow by the turning vanes in Corner D or could be caused by the presence of the bellmouth contour.

Additional velocity data were collected by using the hand-held anemometer along four vertical survey planes just upstream of the spray bars at a test section setting of $100 \mathrm{mph}$ (Fig. 20). These data also show the deficit at 13 to $16 \mathrm{ft}$ above the tunnel floor, although not as large a deficit as noted in the previous paragraph.

\section{Flow Visualization}

Figure 1 indicates the locations in which flow visualization was used to study the flow in certain areas of the tunnel. Descriptions of and results from the studies conducted in each area follow.

Upstream of fan (smoke). A smoke canister was attached to a long pole so that it could be placed at any location along the survey plane upstream of the fan. The test was conducted at a test section velocity of $100 \mathrm{mph}$. The smoke paths were straight down the tunnel and into the fan from any position; there was very little indication of swirl in the flow.
Downstream of fan (smoke). A smoke canister was attached to a long pole so that it could be placed at any position around the fan drive motor housing. This method provided a good mapping of the flow field around the drive motor housing. The test was conducted at a test section velocity of $100 \mathrm{mph}$. Reversed flow areas were found along the upper north side of the drive motor housing as well as in areas along the north side of the housing in which there was almost no flow. These results are similar to results seen in the NASA Ames 7- by 10-ft Wind Tunnel. ${ }^{4}$ (The Lewis IRT is modeled after the Ames 7- by 10-ft Wind Tunnel.) The drive motor housing supports block the flow, which, in turn, could cause the problem areas on the north side of the housing. The smoke indicated that the flow exiting from under the drive motor housing between the supports turned sharply upward toward the tunnel ceiling.

Corner $\mathrm{C}$ (tufts). The tufts indicated that the air speed decreased toward the outside of the turn (north side) as was seen from the hand-held anemometer velocity data. There was very little difference vertically between the tufts, but there was a definite decrease in flow speed across the tunnel at the corner.

CornerD and settling chamber (smoke and tufts). Smoke canisters were attached to the tunnel floor and walls (including the splitter wall) at several locations. A smoke canister attached to a pole was also used in this area. Tufts were attached to the splitter wall and the bellmouth floor contour. There was fairly good flow into the inlet from all locations surveyed in the settling chamber; no major problem areas were discovered. The rounded transition step from the settling chamber floor to the bellmouth contour did disrupt the path along the tunnel floor surfaces. Neither smoke nor tufts indicated any apparent separation in the bellmouth.

\section{Summary of Results}

The data collected in the studies reported herein will be used to determine areas in the facility where modifications can be made to improve flow quality and efficiency. These data can be used to provide boundary or starting conditions for computer simulations of the flow field in the actual facility.

The following are the results of the studies:

1. The Mach number distribution and variation in the test section was generally acceptable (0.005 Mach number variation).

2. Significant flow angularity existed in both the pitch and yaw planes (flow quality goal of $\pm 0.10^{\circ}$ flow angle variation).

3. A velocity gradient existed in the flow at the cooler inlet, which could affect the efficiency of the cooler.

4. The velocity and flow angularity surveys downstream of the cooler indicate poor flow quality caused by the shape and blockage of the cooler. 
5. Flow visualization tests indicated flow problems downstream of the drive fan along the north side of the drive motor housing. Areas of no flow and reversed flow were indicated by the smoke patterns in this area.

\section{Concluding Remarks}

A series of studies were conducted in the NASA Lewis Icing Research Tunnel to determine the flow quality in the test section and throughout the tunnel loop. While the primary intent of this report is to provide documentation of the data collected during these studies, some recommendations are given for follow-on tests and possible tunnel modifications.

For follow-on tests,

1. The flow angularity probes should be calibrated for the specific test conditions.

2. Better flow angle probe and rake alignment measurements need to be made to increase measurement accuracy.

3. A tighter grid of points across the test section would aid in mapping the flow field at each test section station.

4. The design of the probe supports (support length and diameter changes) must be updated to minimize any aerodynamic interference from the probe support and rake body.

5. Velocity distribution data should be collected upstream of the fan but closer to the fan face than the data taken at survey plane 1 . The velocity profile just upstream of the fan face is probably somewhat flatter than at survey plane 1 because of mixing.

6. Traversing plate/wind anemometer surveys should be made downstream of the drive fan motor housing to better quantify the flow in that area. In order to separate effects from the fan and the drive motor housing, two survey planes are required: one just downstream of the fan and the second downstream on the drive motor housing.

7. Better definition of the flow entering and exiting the cooler is required. At least one vertical and two or three horizontal traversing plate surveys should be made at each of these stations.

8. Additional vertical and horizontal surveys (traversing plate and wind anemometer) should be made in the settling chamber (Corner D). Two additional vertical surveys, one at the tunnel centerline and the second near the north settling chamber wall, will help determine if the turning vanes in Corner D are overturning the flow. Three horizontal surveys at about $1 / 4,1 / 2$, and $3 / 4$ of the tunnel height will better define the flow differences between the outer (main) and inner (secondary) coolers.

9. Boundary layer thickness measurements should be made at the inlet and exit of the test section. The boundary layer size and growth will affect the icing cloud size.

10. Velocity distribution data should be collected upstream of the turning vanes in Corner B. This information coupled with the data taken downstream of the turning vanes (survey plane 1) give an indication of the effectiveness of the turning vanes.

For tunnel modifications,

1. Because the cooler seems to cause the biggest flow distortions, additional measurements at the cooler inlet and exit have been suggested. The turning vanes along the downstream side of the cooler could be overturning the flow so that it cannot fill the void caused by the upstream fairing. Additional investigation using different vane geometries is recommended.

2. Investigation into replacing the existing cooler with a flat cooler is also advised. A flat cooler would eliminate the flow distortions caused by the current folded cooler geometry and should provide some measure of flow conditioning (analogous to a flow conditioning screen of honeycomb).

3. The "bump" at the inlet of the bellmouth (transition between the settling chamber and the bellmouth) should be removed. The smoke flow visualization showed that this contour affected the flow path. ${ }^{\dagger}$

\section{Appendix}

The test section flow field survey data are summarized in this appendix (see Figs. 21 to 40). Total and static pressures, $P_{O}$ and $P_{S}$, respectively, and $M a c h$ number, $M$, are normalized by freestream conditions (subscript FS) and are presented as surface plots. Flow angularity data are given in vector plots. Each set of four plots describes the flow quality at one survey station at one velocity setting.

\section{$\underline{\text { References }}$}

1. Arrington, E.A., Pickett, M.T., and Sheldon, D.W., "Flow Quality Studies of The NASA Lewis Research Center Icing Research Tunnel Diffuser Section,"NASA TM-106311, Jan. 1994.

2. Soeder, R.H., and Andracchio, C.R., "NASA Lewis Icing Research Tunnel Used Manual," NASA TM102319, June 1990.

3. Henderson, A., Jr., and McKinney, L.W., "Overview of the 1989 Wind Tunnel Calibration Workshop," NASA TP-3393, Aug. 1993.

4. Wadcock, A.J., "The NASA Ames $7 \mathrm{ft} \times 10 \mathrm{ft}$ Wind Tunnel-Present Flow Quality and Recommendations for Improvement," Analytical Methods Report 8705, July 1987.

\footnotetext{
${ }^{\dagger}$ By the time of this writing, this recommendation had been implemented.
} 
Table 1.-Summary of Test Section Flow Quality Goals for the NASA Lewis Research Center Wind Tunnel Facilities

\begin{tabular}{|l|c|c|}
\hline \multirow{1}{*}{\multicolumn{1}{|c|}{$\begin{array}{c}\text { Flow quality } \\
\text { parameter }\end{array}$}} & \multicolumn{2}{|c|}{ NASA Lewis facility } \\
\cline { 2 - 3 } & $\begin{array}{c}\text { 8- by 6-ft SWT } \\
\text { 9- by 15-ft LSWT } \\
\text { 10- by 10-ft SWT }\end{array}$ & $\begin{array}{c}\text { Icing Research } \\
\text { Tunnel } \\
\text { (IRT) }\end{array}$ \\
\hline Mach number variation & 0.005 & 0.005 \\
Flow angularity & $0.25^{\circ}$ & $0.10^{\circ}$ \\
Turbulence intensity & $0.25 \%$ & $0.50 \%$ \\
Total temperature variation & $4^{\circ} \mathrm{F}$ & $2^{\circ} \mathrm{F}$ \\
\hline
\end{tabular}

SWT, Supersonic Wind Tunnel; LSWT, Low-Speed Wind Tunnel

Table 2.-Average Test Section Settings/Conditions During Test Section Flow Field Surveys

\begin{tabular}{|c|c|c|c|c|c|c|c|}
\hline $\begin{array}{c}\text { Nominal } \\
\text { velocity, } \\
\text { mph }\end{array}$ & $\begin{array}{c}\text { Actual } \\
\text { velocity, } \\
\mathrm{mph}\end{array}$ & $\begin{array}{c}\text { Actual } \\
\text { velocity, } \\
\mathrm{ft} / \mathrm{sec}\end{array}$ & $\begin{array}{c}\text { Mach } \\
\text { number }\end{array}$ & $\begin{array}{c}\text { Total } \\
\text { pressure, } \\
\text { psia }\end{array}$ & $\begin{array}{c}\text { Static } \\
\text { pressure, } \\
\text { psia }\end{array}$ & $\begin{array}{c}\text { Dynamic } \\
\text { pressure, } \\
\text { psia }\end{array}$ & $\begin{array}{c}\text { Total } \\
\text { temperature, } \\
\mathbf{R}\end{array}$ \\
\hline 50 & 49.7 & 72.9 & 0.065 & 14.311 & 14.269 & 0.042 & 532 \\
100 & 100.0 & 146.7 & .130 & 14.310 & 14.143 & .167 & 532 \\
150 & 150.8 & 221.1 & .195 & 14.309 & 13.934 & .375 & 532 \\
200 & 202.2 & 296.5 & .261 & 14.308 & 13.645 & .663 & 534 \\
250 & 254.5 & 373.2 & .328 & 14.308 & 13.283 & 1.025 & 537 \\
275 & 280.9 & 412.0 & .361 & 14.303 & 13.075 & 1.229 & 538 \\
300 & 308.0 & 451.7 & .396 & 14.306 & 12.849 & 1.457 & 540 \\
\hline
\end{tabular}

Table 3.-Variation in Flow Parameters Over Survey Plane 2

(Turntable Centerline)

\begin{tabular}{|c|c|c|c|c|}
\hline $\begin{array}{c}\text { Nominal } \\
\text { velocity, } \\
\text { mph }\end{array}$ & $\begin{array}{c}\text { Total } \\
\text { pressure } \\
\text { variation, } \\
\text { psia }\end{array}$ & $\begin{array}{c}\text { Static } \\
\text { pressure } \\
\text { variation, } \\
\text { psia }\end{array}$ & $\begin{array}{c}\text { Mach } \\
\text { number } \\
\text { variation }\end{array}$ & $\begin{array}{c}\text { Mach } \\
\text { number } \\
\text { ceiling } \\
\text { deficit }\end{array}$ \\
\hline 50 & 0.015 & 0.013 & 0.007 & ----- \\
100 & .015 & .013 & .005 &.--- \\
150 & .016 & .019 & .002 & 0.007 \\
200 & .018 & .020 & .003 & .008 \\
250 & .025 & .034 & .006 & .015 \\
275 & .023 & .024 & .005 & .012 \\
300 & .010 & .068 & .011 & .011 \\
\hline
\end{tabular}



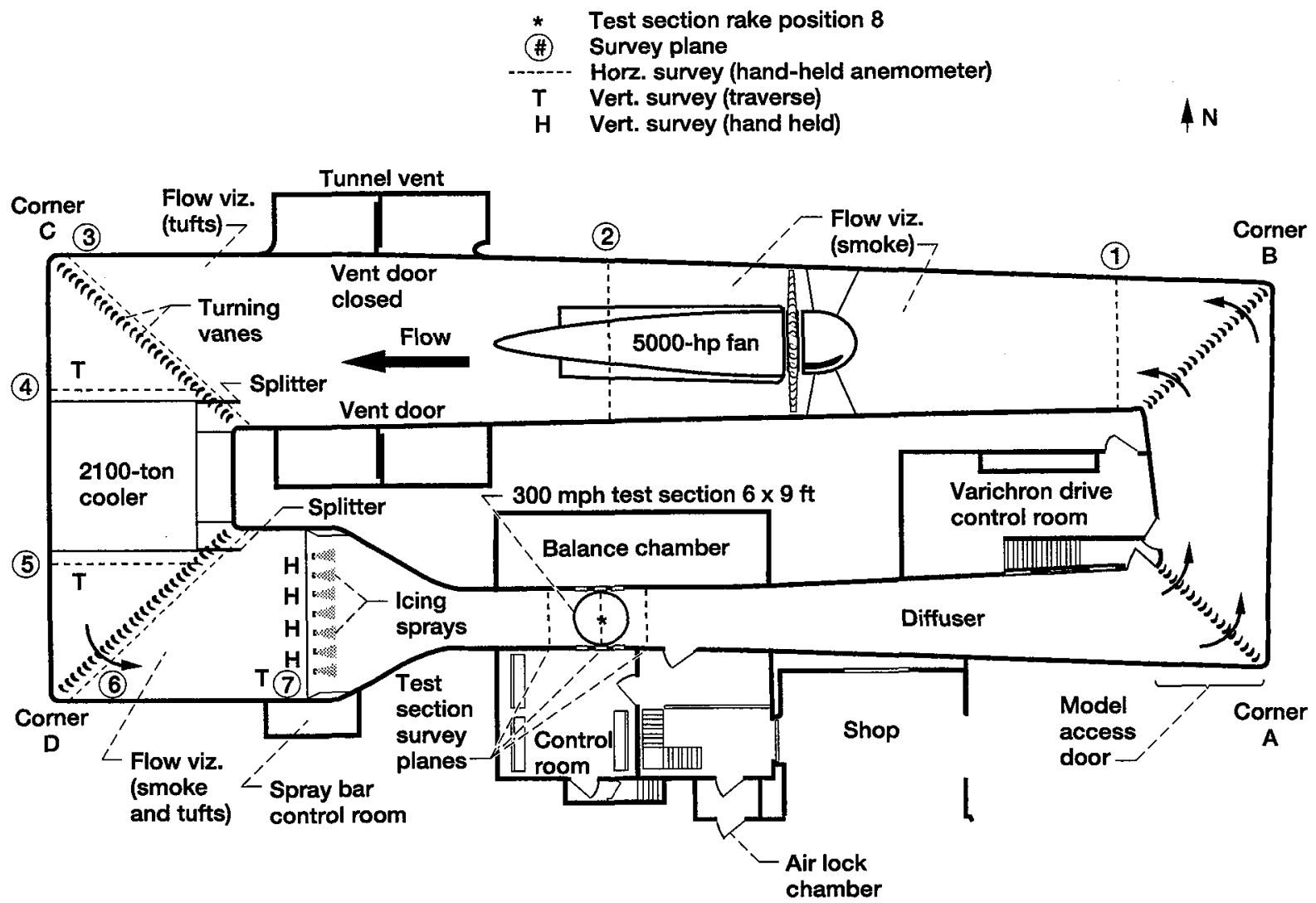

Figure 1.-Plan view of Icing Research Tunnel, shop, and control room, showing areas studied and measurements made in each area. 

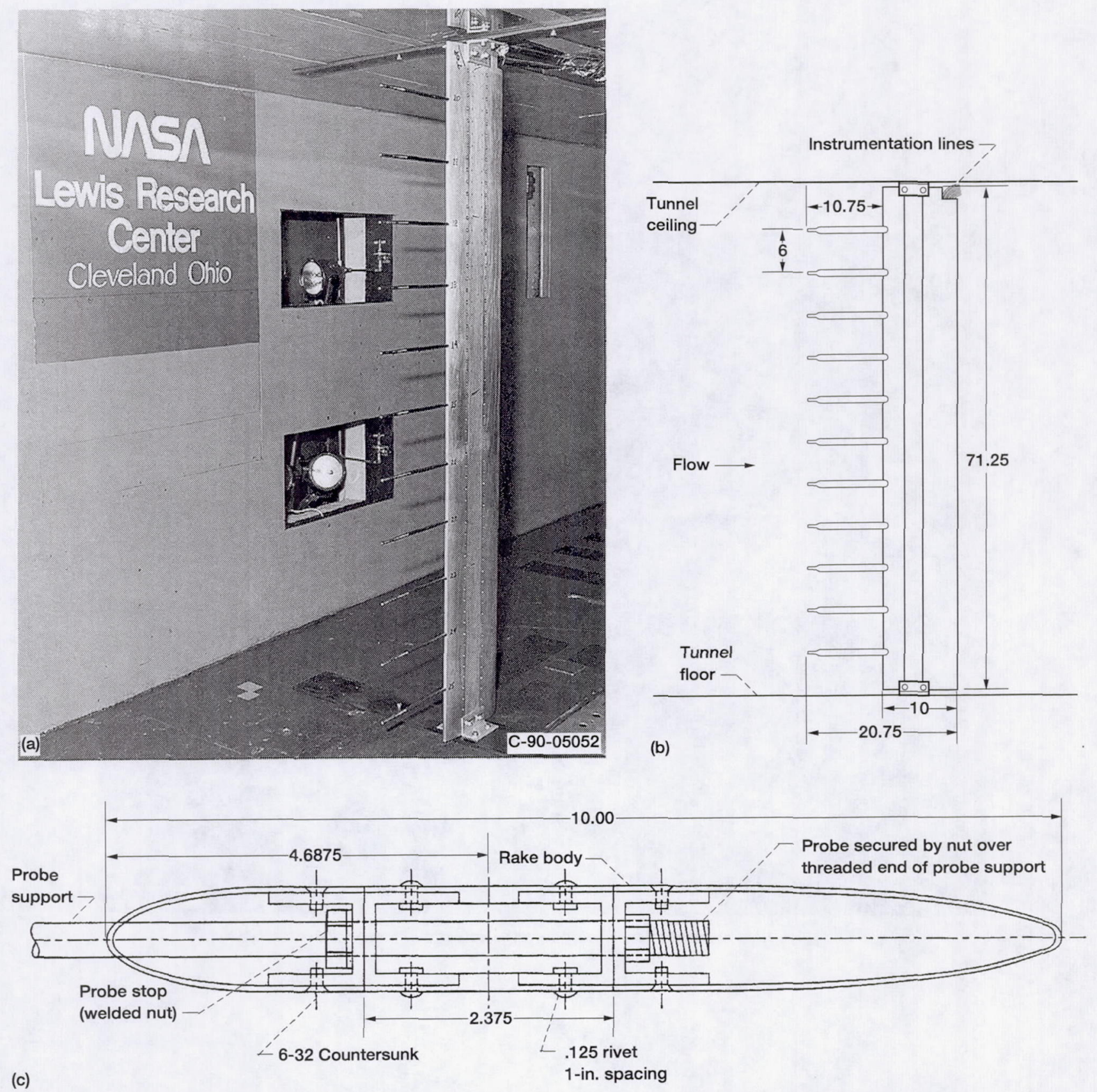

Figure 2.-Test section survey rake. (Dimensions are in inches.) (a) Typical installation in IRT test section. (b) Rake dimensions. (c) Cross section of rake. 


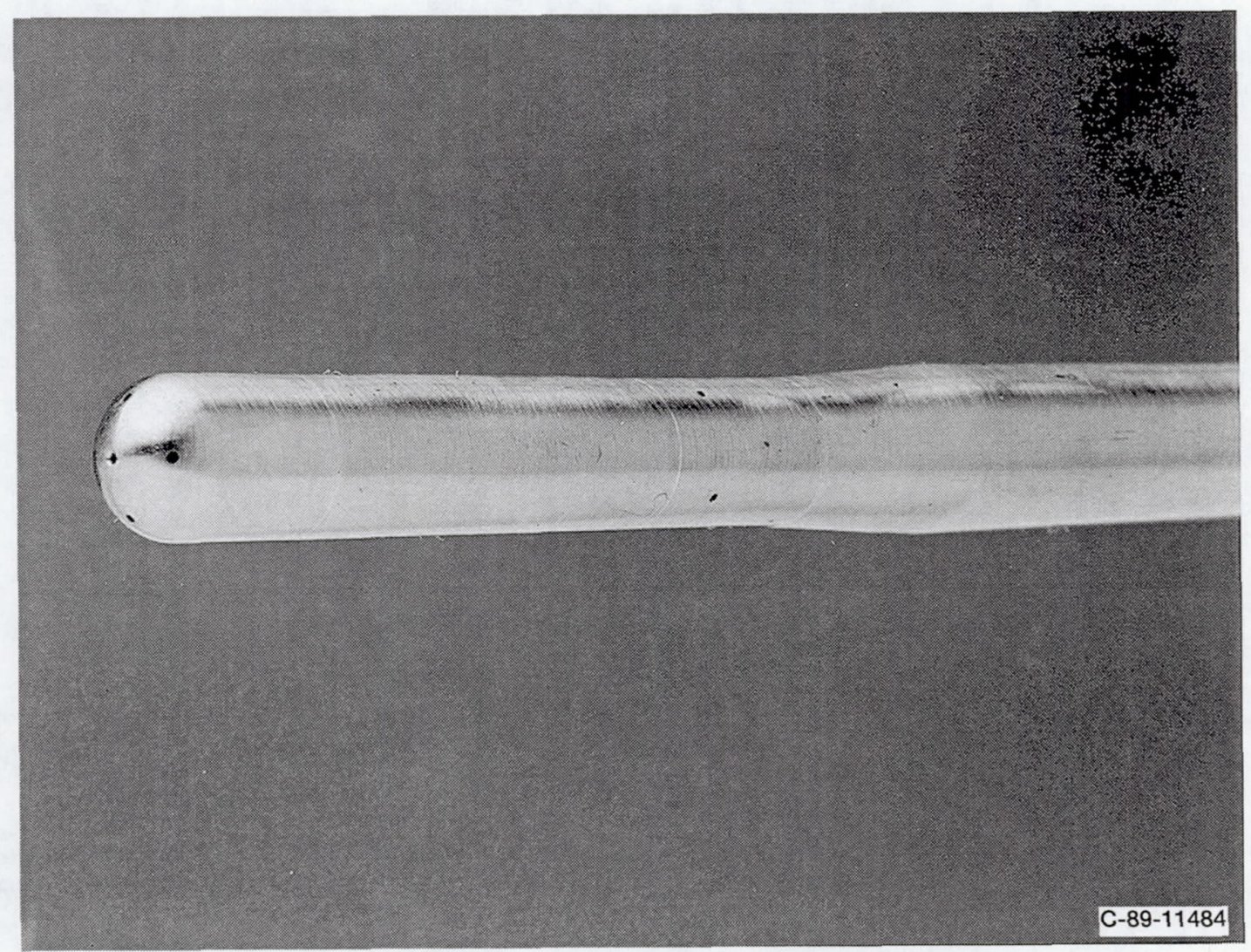

Figure 3.-Five-hole hemispherical-head flow angularity probe (probe diameter, $3 / 8 \mathrm{in}$.). 

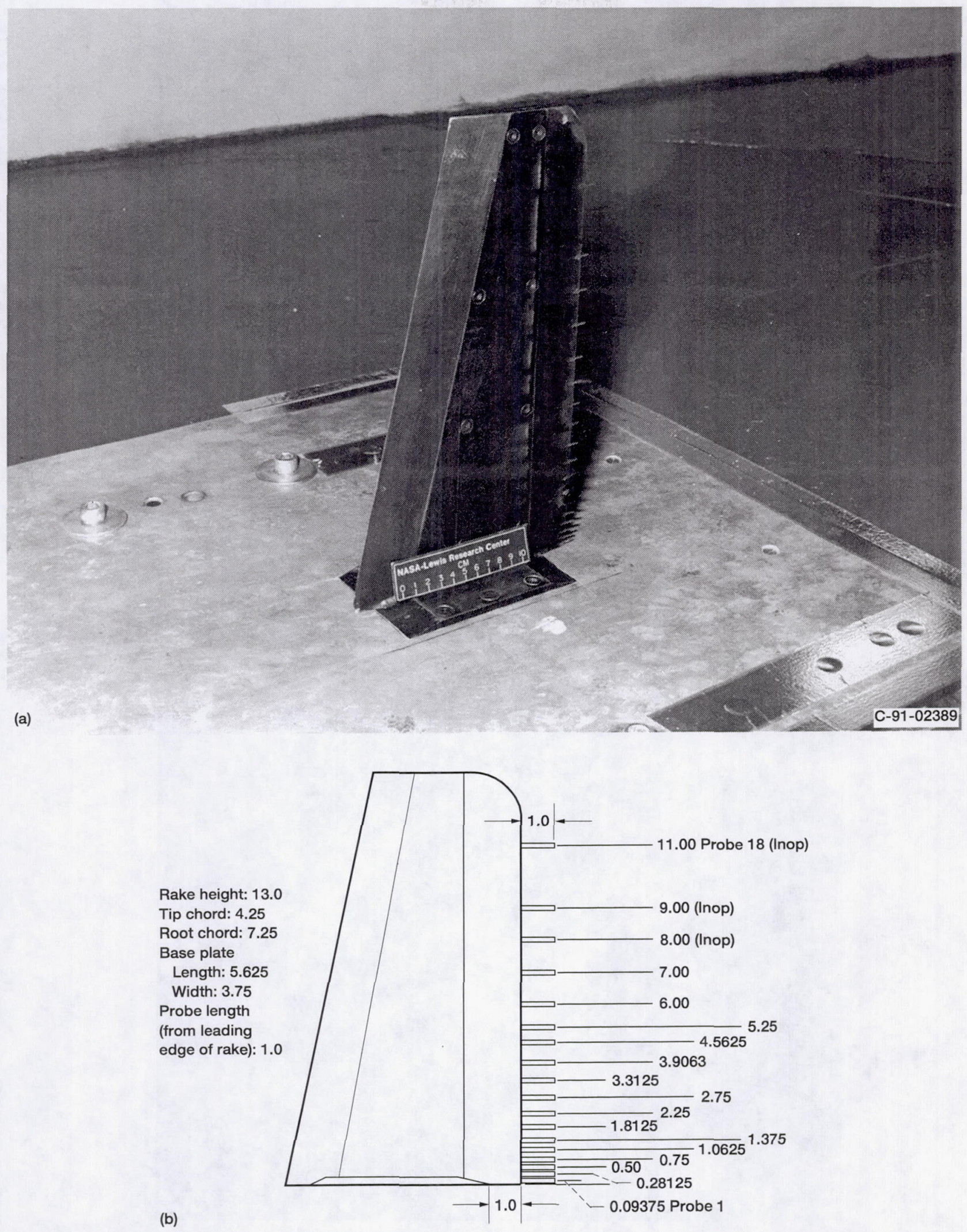

Figure 4.-Boundary layer rake used in test section surveys. (a) Rake installation. (b) Rake layout. (Dimensions are in inches.) 

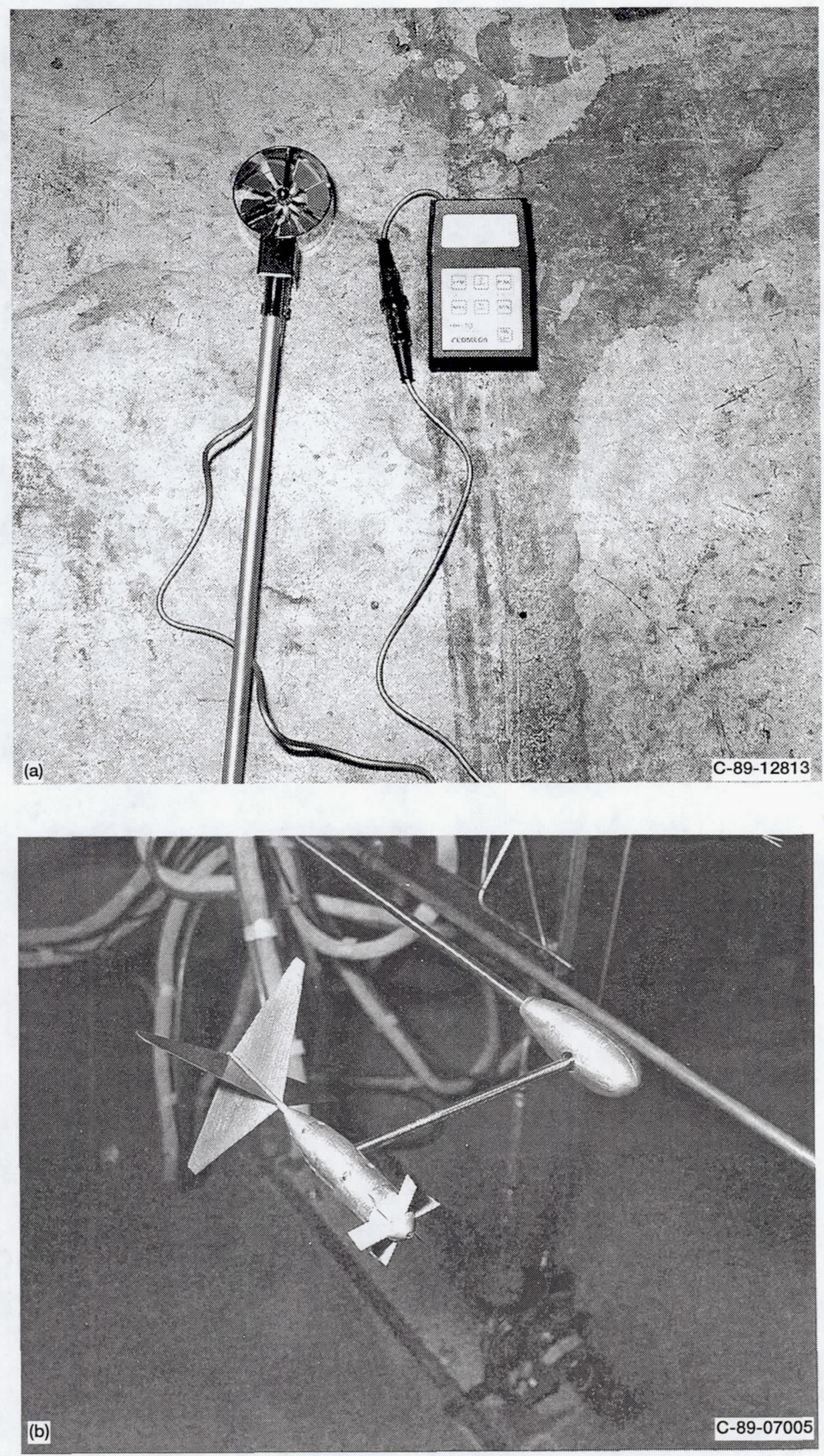

Figure 5.-Wind anemometers used in flow quality studies. (a) Hand-held anemometer. (b) Vane anemometer. 


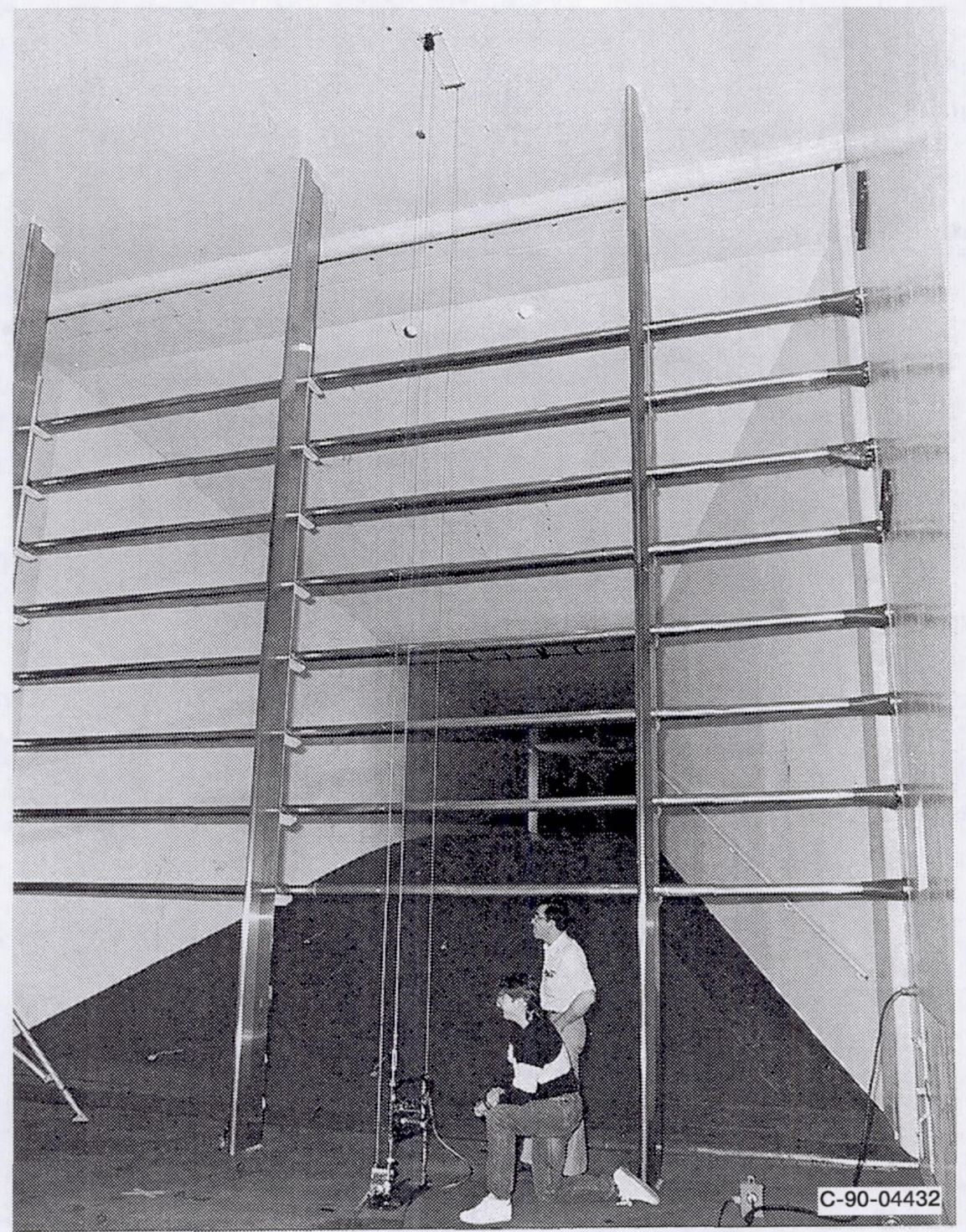

Figure 6.-Traversing plate with vane anemometer set up for vertical survey in Corner D (upstream of spray bars). 


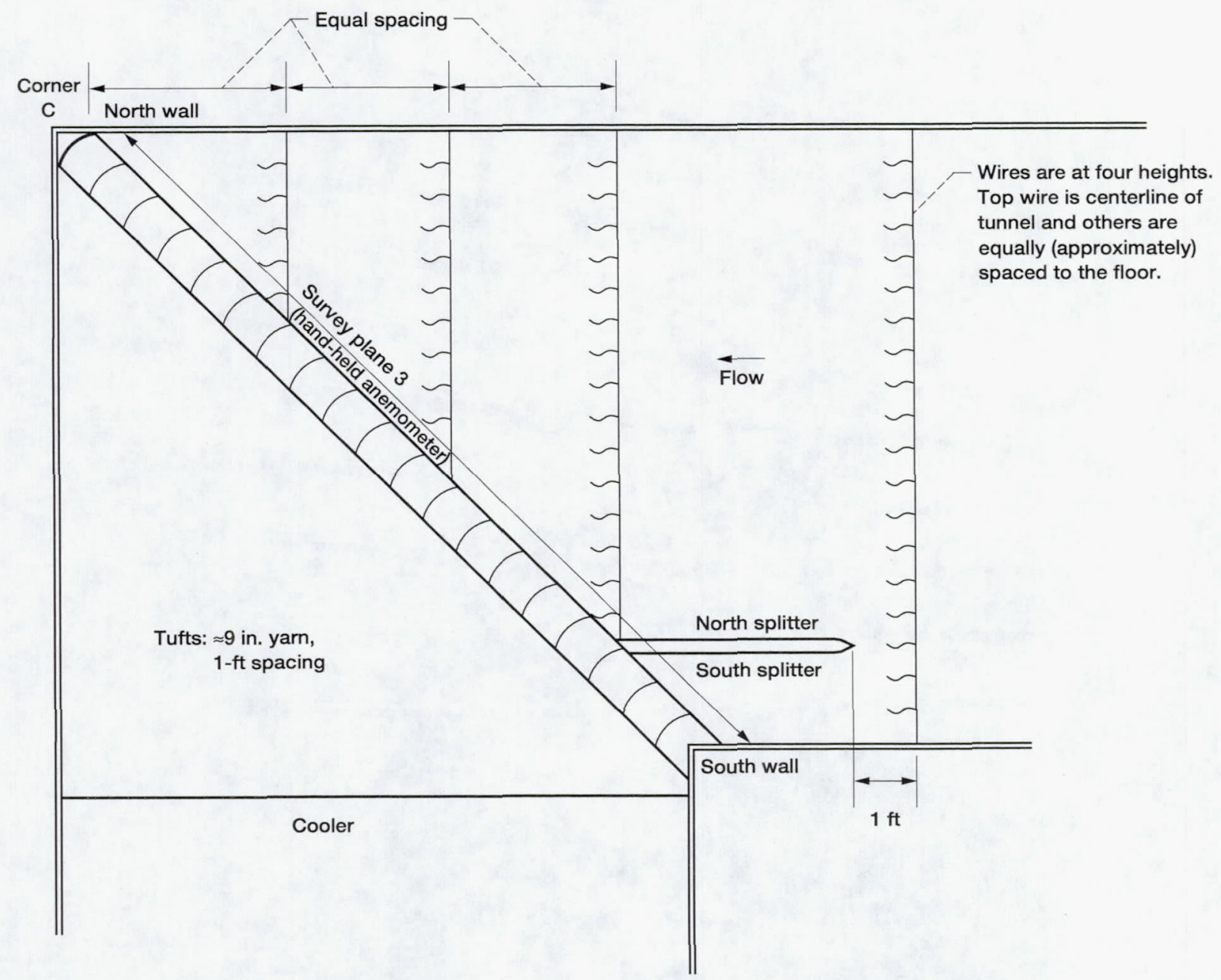

Figure 7.-Corner $\mathrm{C}$ test setup showing tuft flow visualization installation and velocity survey plane. 


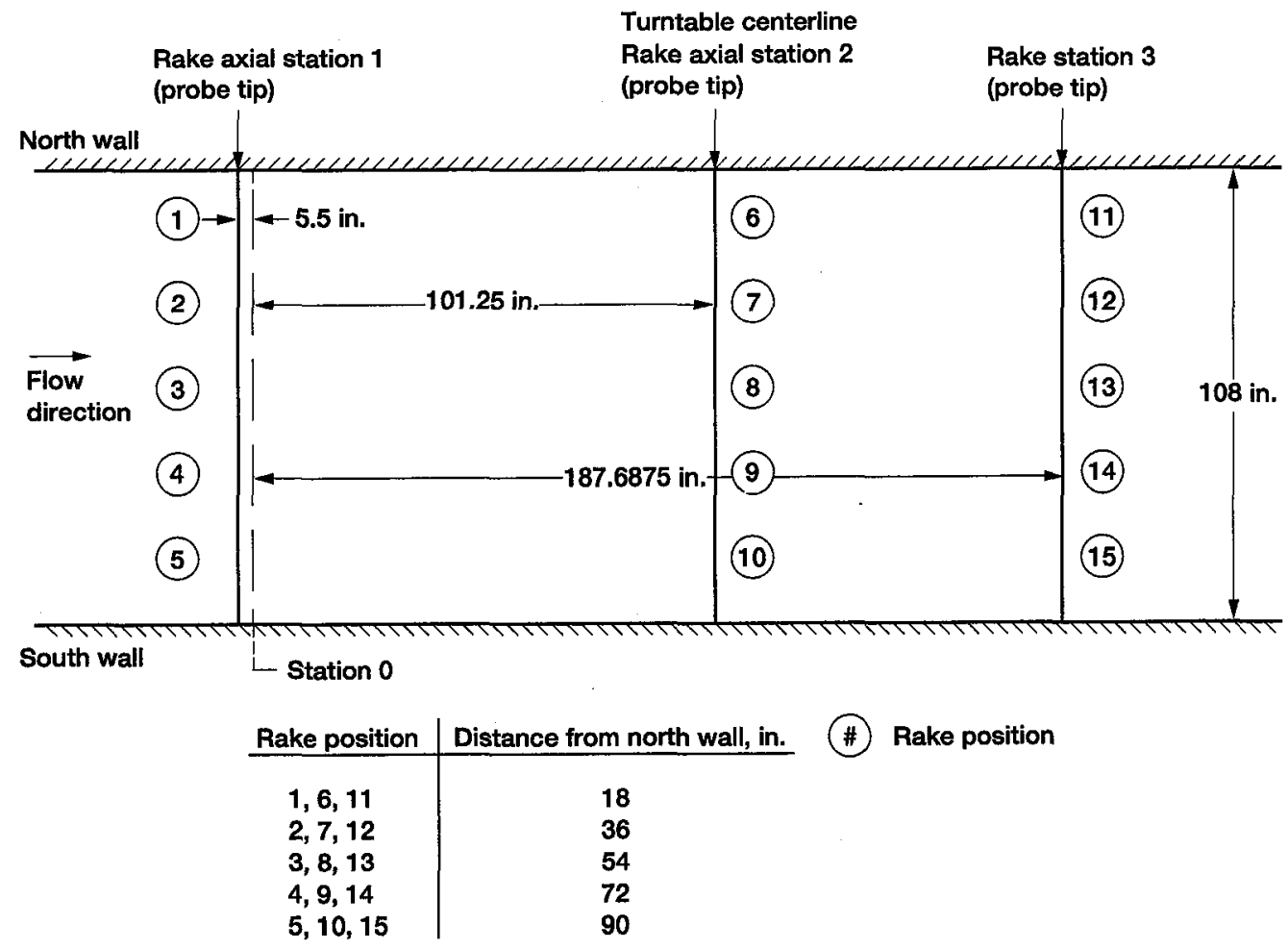

Figure 8.-IRT test section layout showing survey rake positions. Overall test section length is $240 \mathrm{in}$. (20 ft). 

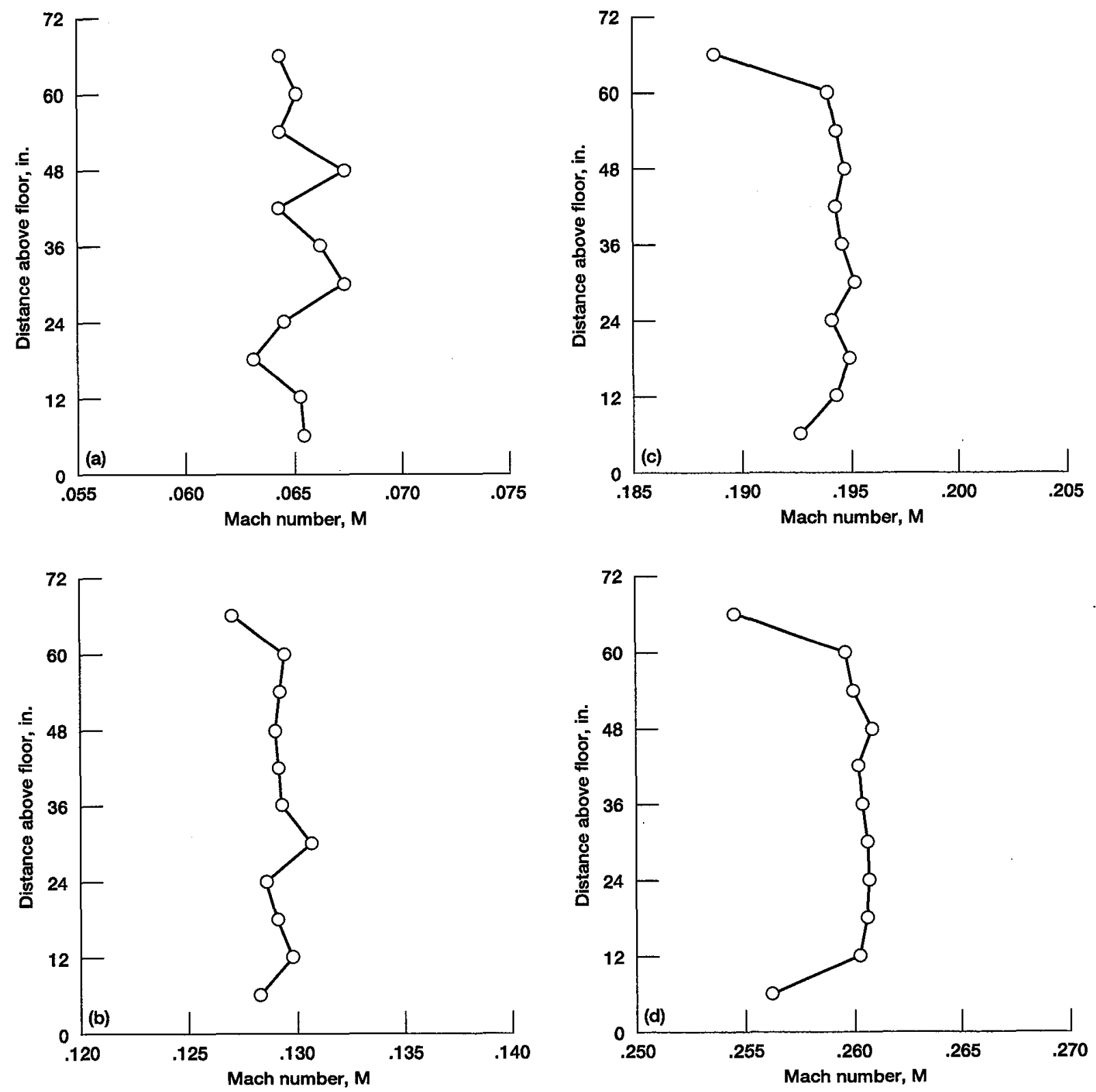

Figure 9.-Mach number survey results at axial station 101 at test section centerline (rake position 8). (a) $V_{\mathrm{TS}}=\mathbf{5 0} \mathrm{mph}$. (b) $V_{\mathrm{TS}}=100 \mathrm{mph}$. (c) $V_{\mathrm{TS}}=150 \mathrm{mph}$. (d) $V_{\mathrm{TS}}=200 \mathrm{mph}$. 

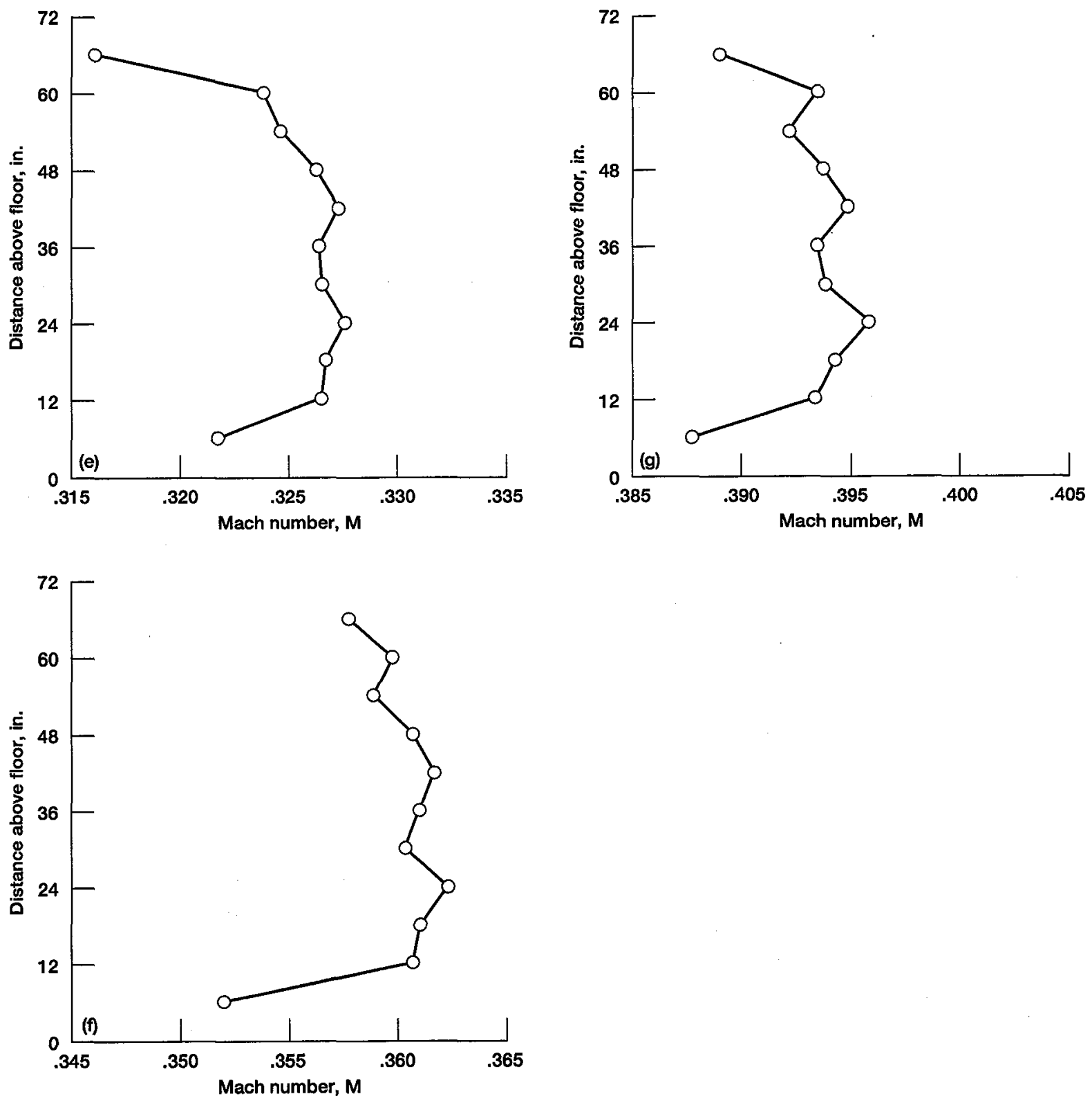

Figure 9.-Concluded. (e) $V_{T S}=250 \mathrm{mph}$. (f) $V_{T S}=275 \mathrm{mph}$. (g) $V_{T S}=300 \mathrm{mph}$. 


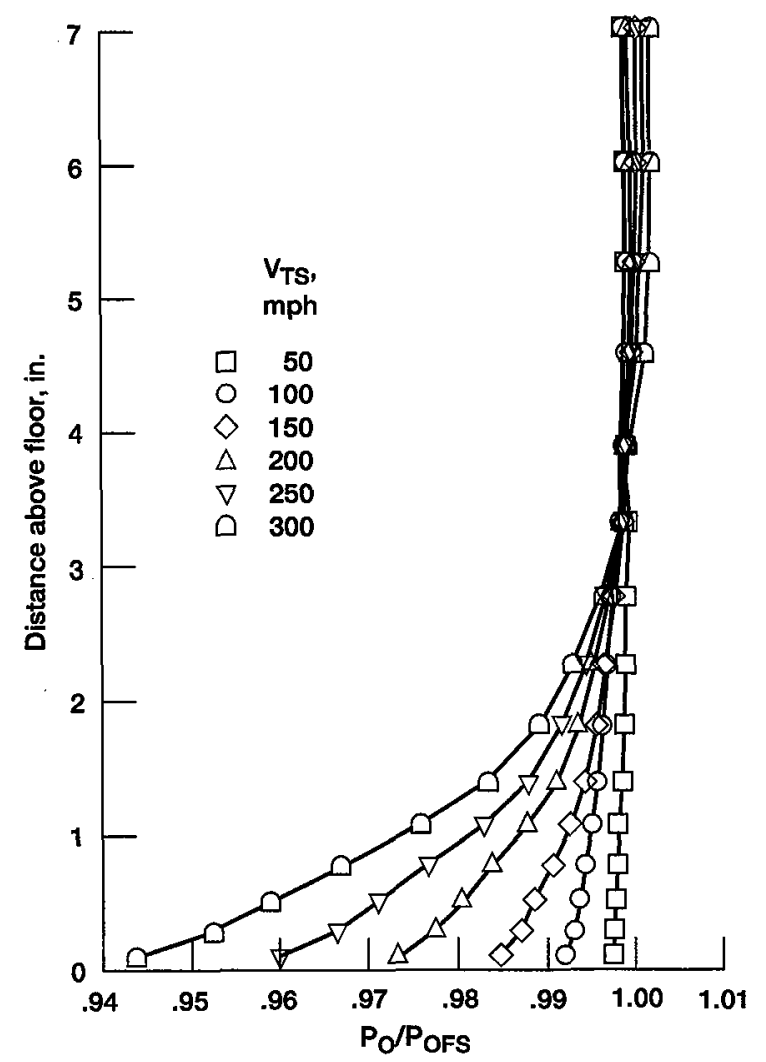

Figure 10.-Boundary layer total pressure distribution on test section floor at axial survey station 2 (test section station 101).

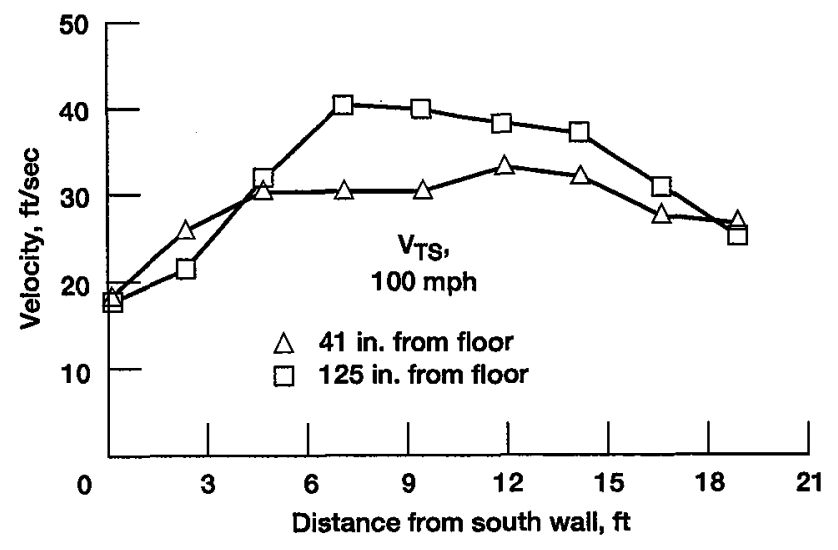

Figure 11.-Velocity distribution along survey plane 1 (Corner B) upstream of drive fan. Data were collected using hand-held anemometer.

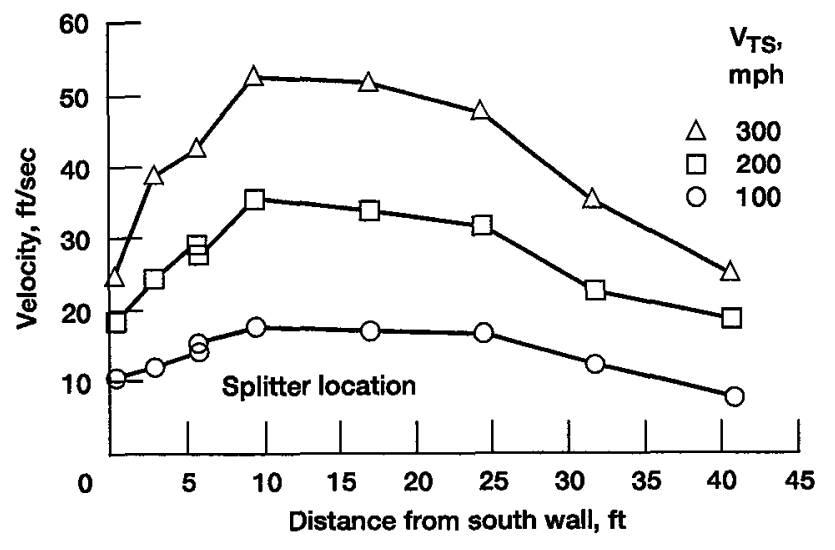

Figure 12.-Velocity distribution along survey plane 3 (Comer C). Data were collected using hand-held anemometer. 


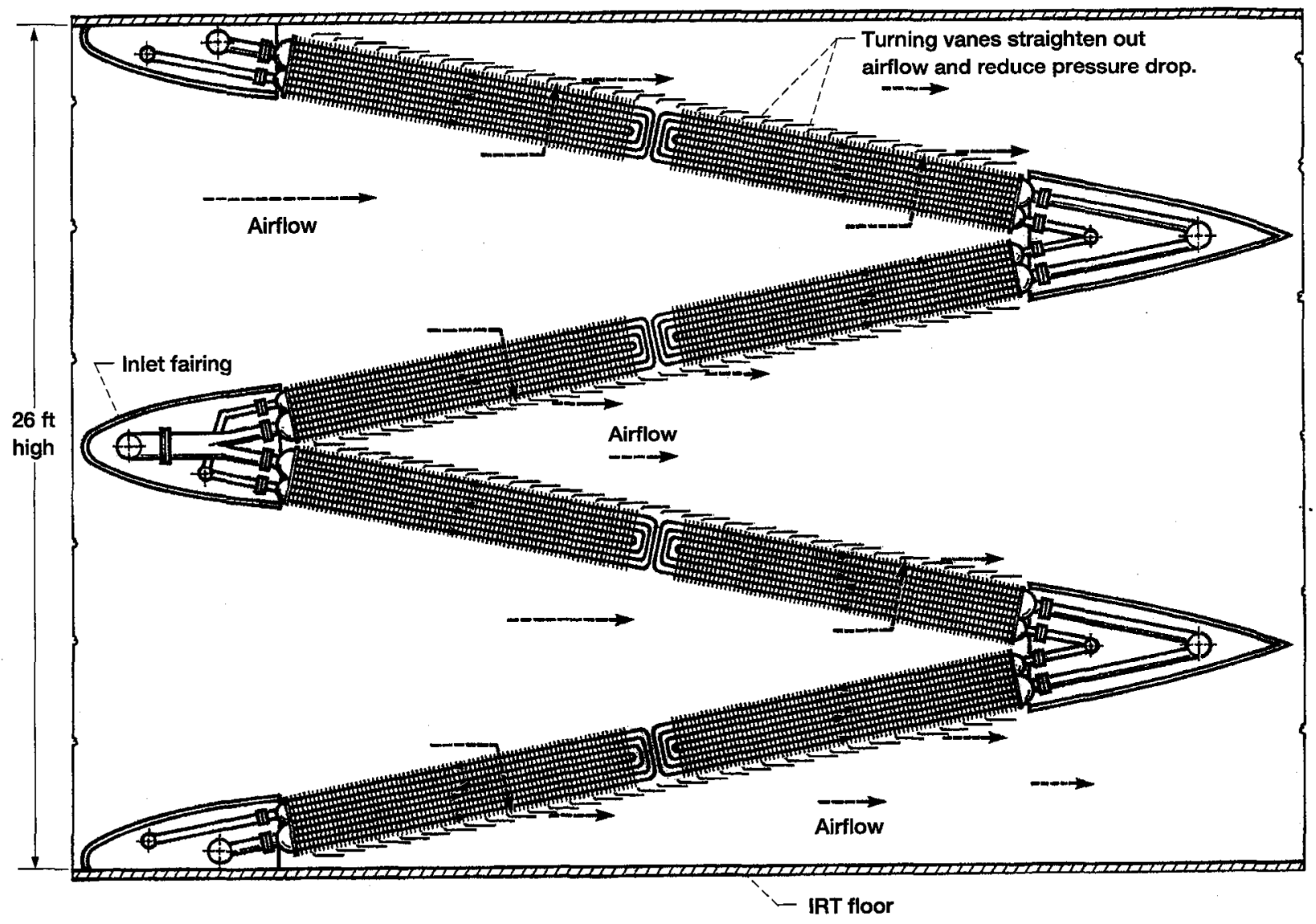

Figure 13.-Elevation view of the cooler in IRT. 

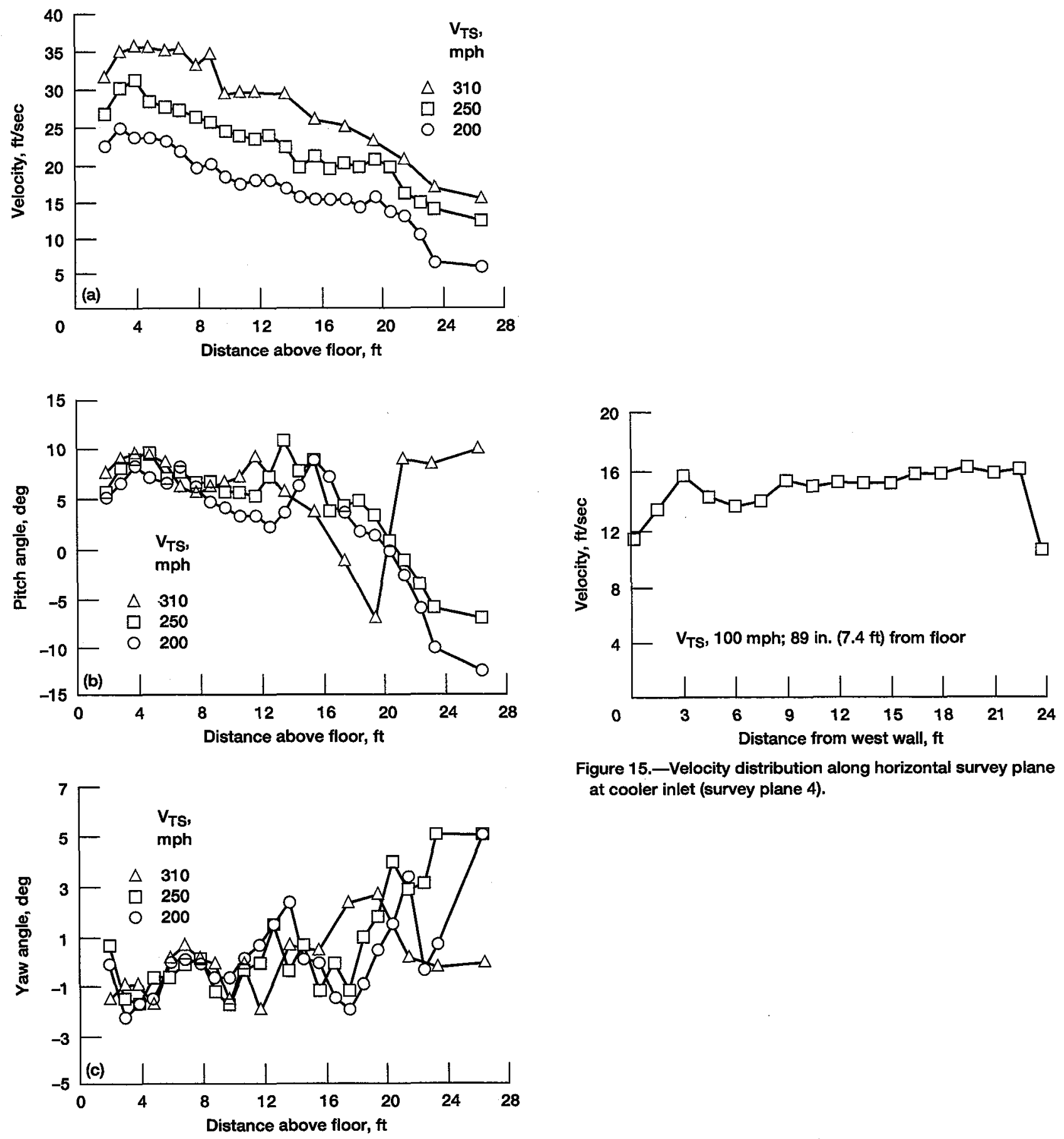

Figure 15.-Velocity distribution along horizontal survey plane at cooler inlet (survey plane 4).

Figure 14.-Vane anemometer data collected along vertical survey plane upstream of IRT cooler (survey plane 4). (a) Velocity data. (b) Pitch flow data (upflow positive). (c) Yaw flow angle data (outflow positive). 

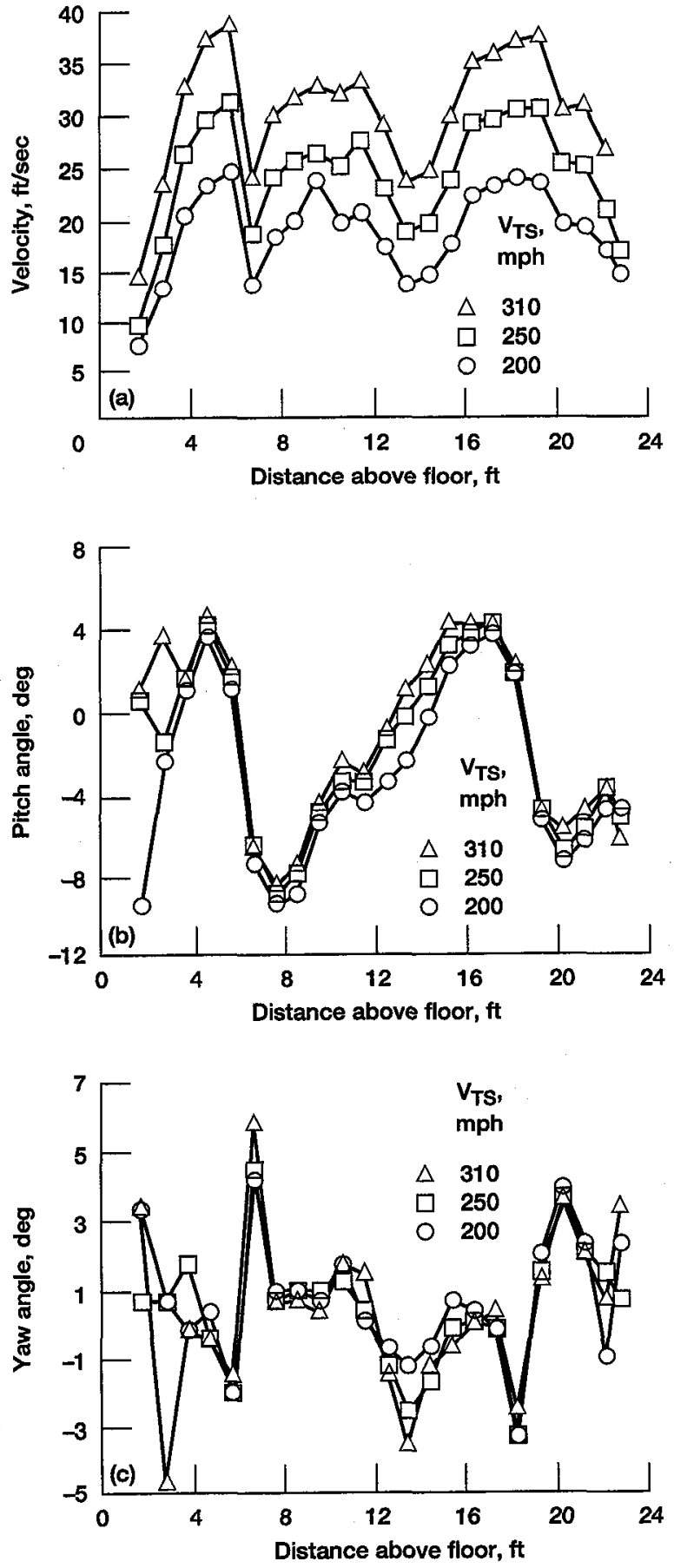

Figure 16.-Vane anemometer data collected along vertical survey plane downstream of IRT cooler (survey plane 5).

(a) Velocity data. (b) Pitch flow angle data (upflow positive).

(c) Yaw flow angle data (outflow positive).

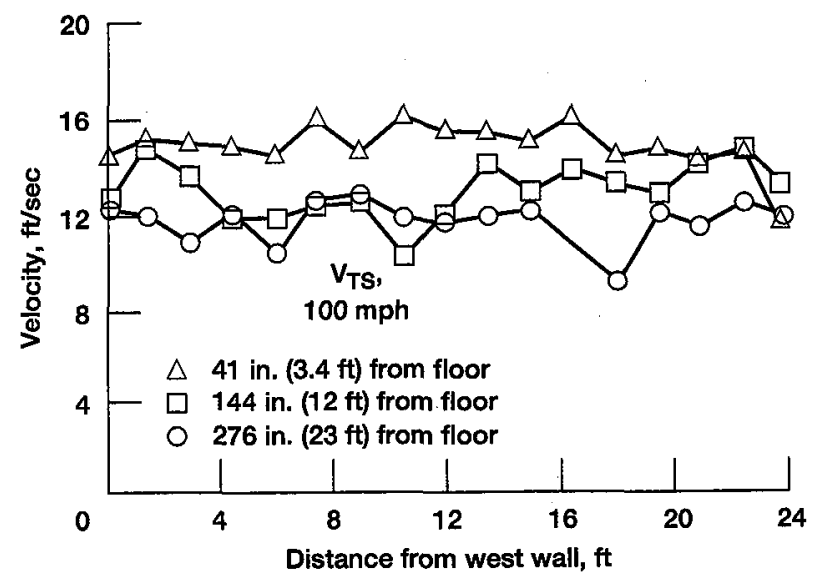

Figure 17.-Velocity distribution along horizontal survey plane at cooler exit (survey plane 5).
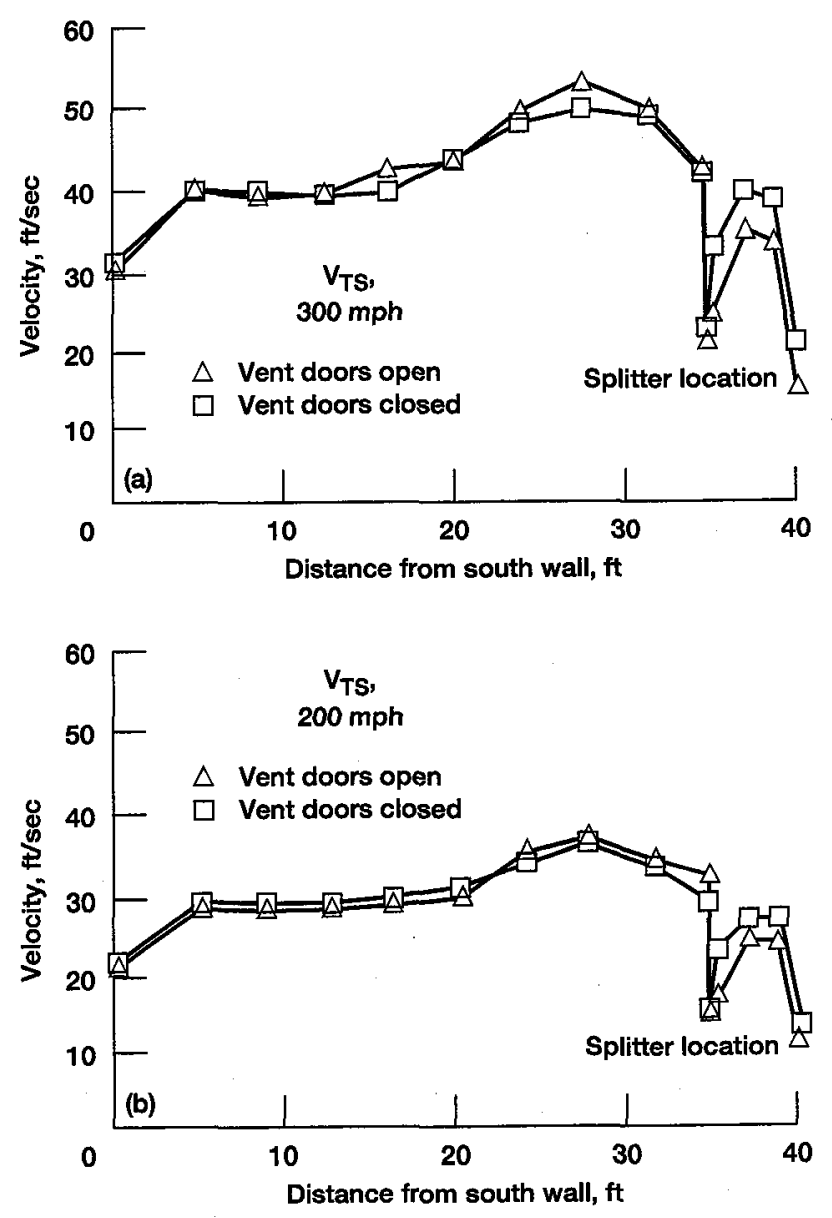

Figure 18.-Velocity surveys along survey plane 6 showing the effects of tunnel vent doors. (a) $V_{\mathrm{TS}}=300 \mathrm{mph}$.

(b) $V_{\text {TS }}=200 \mathrm{mph}$. 

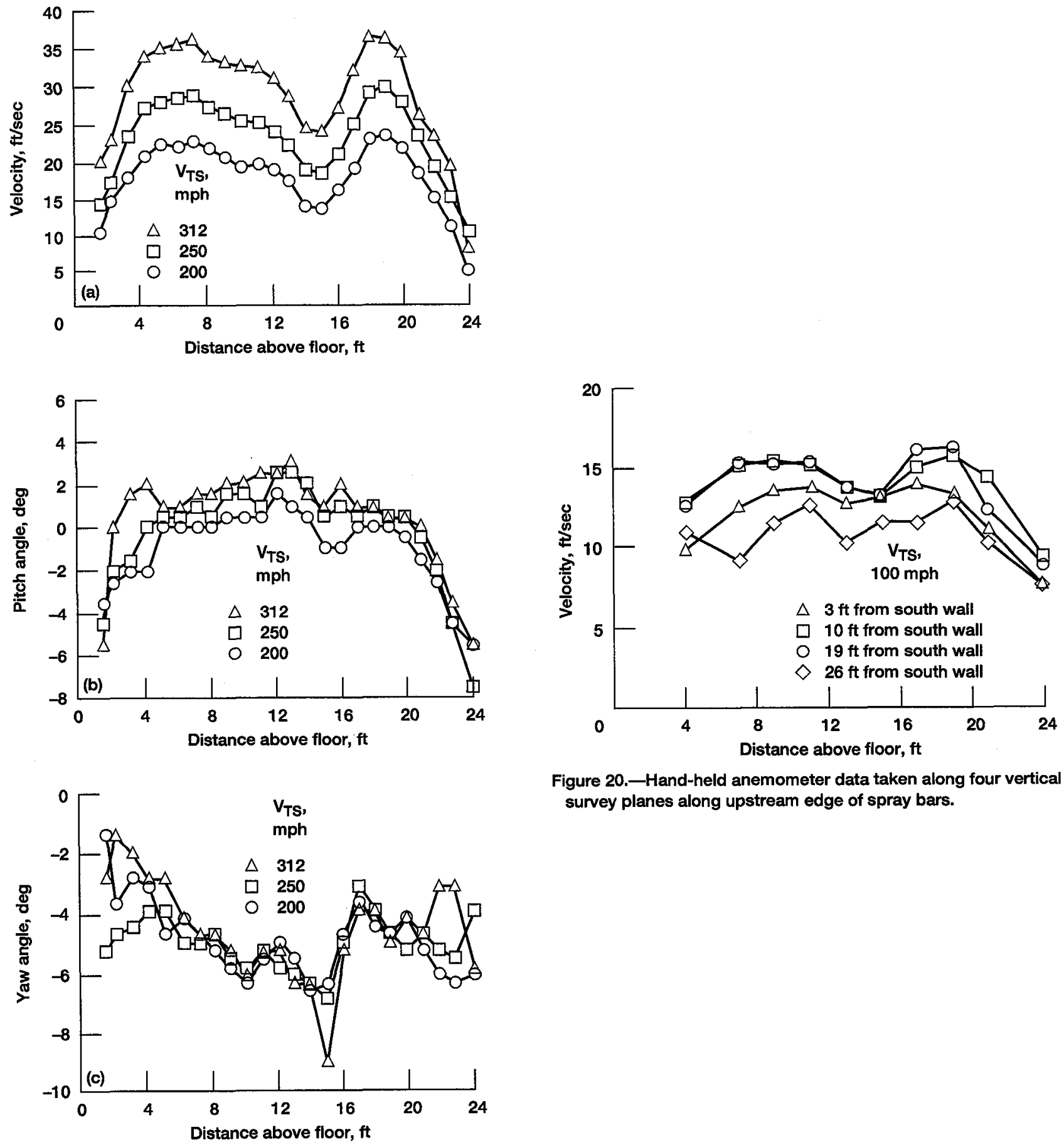

Figure 20.-Hand-held anemometer data taken along four vertical survey planes along upstream edge of spray bars.

Figure 19.-Vane anemometer data collected along vertical survey plane upstream of spray bars (survey plane 5 settling chamber). (a) Velocity data. (b) Pitch flow angle (upflow positive). (c) Yaw flow angle (outflow positive). 

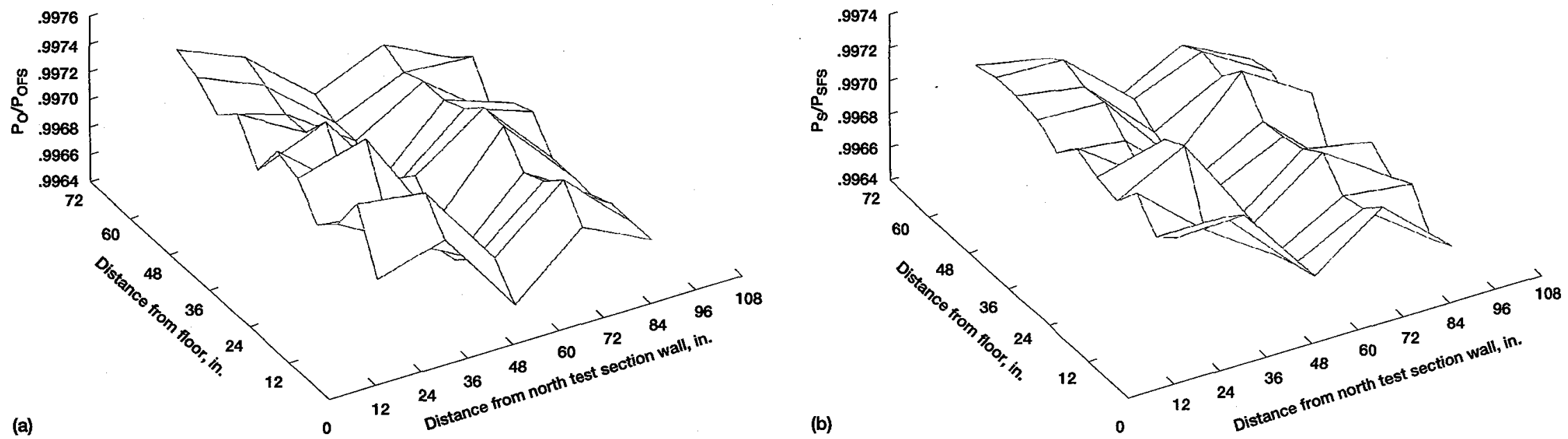

న
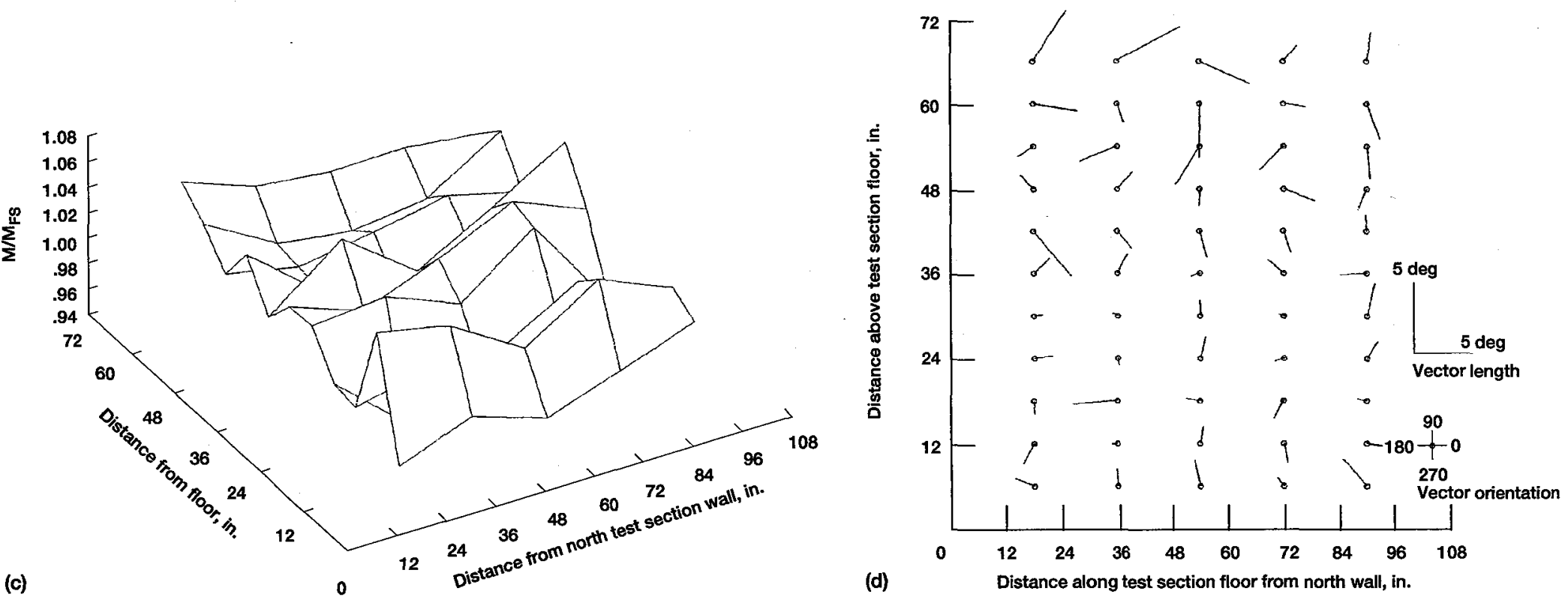

Figure 21.-Test section flow field survey data at inlet survey station for a test section velocity of $50 \mathrm{mph}$. (a) Total pressure ratio. (b) Static pressure ratio. (c) Mach number ratio. (d) Flow angularity vectors. 

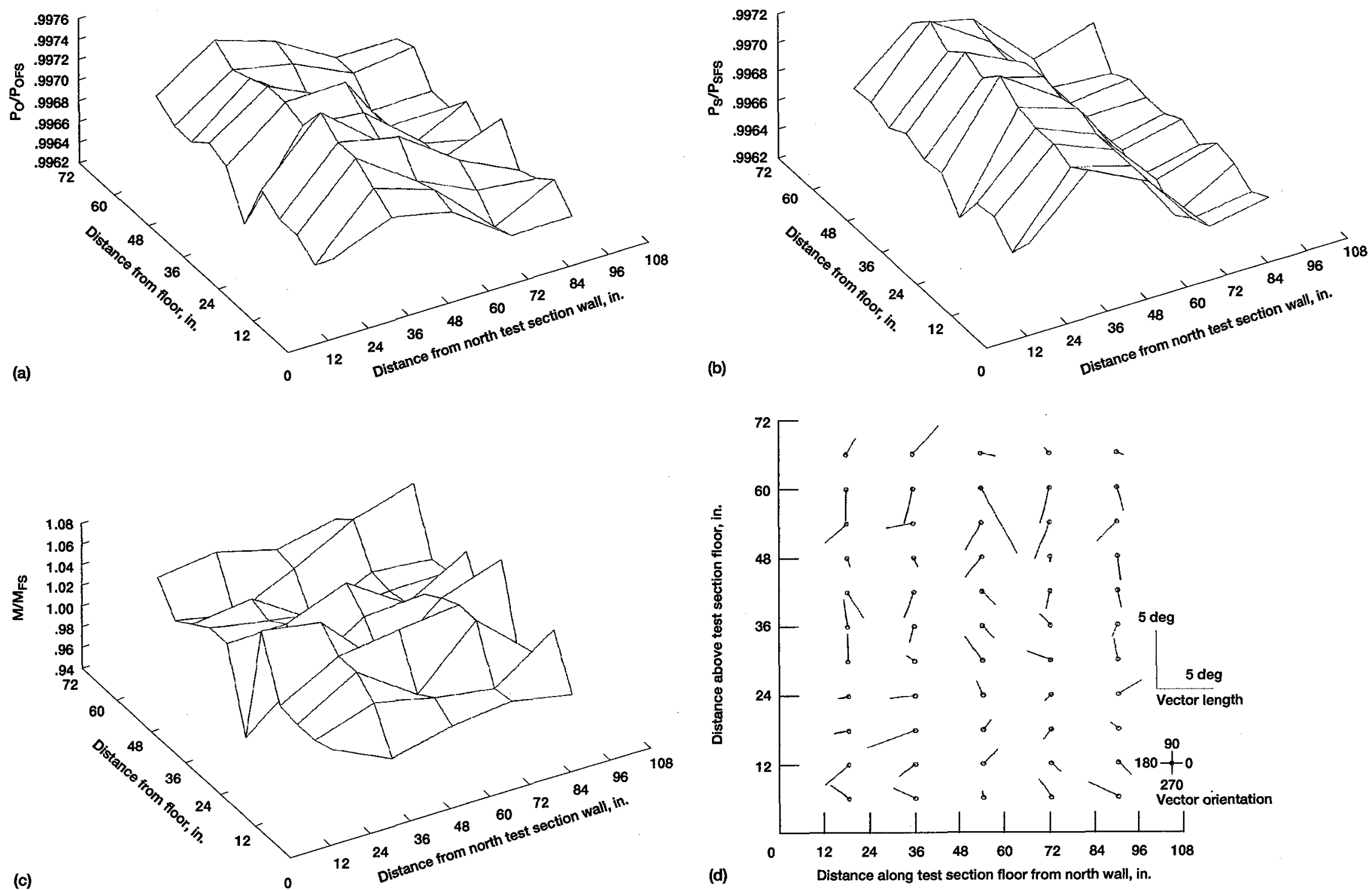

Figure 22.-Test section flow field survey data at test plane survey station for a test section velocity of $50 \mathrm{mph}$. (a) Total pressure ratio. (b) Static pressure ratio. (c) Mach number ratio. (d) Flow angularity vectors. 

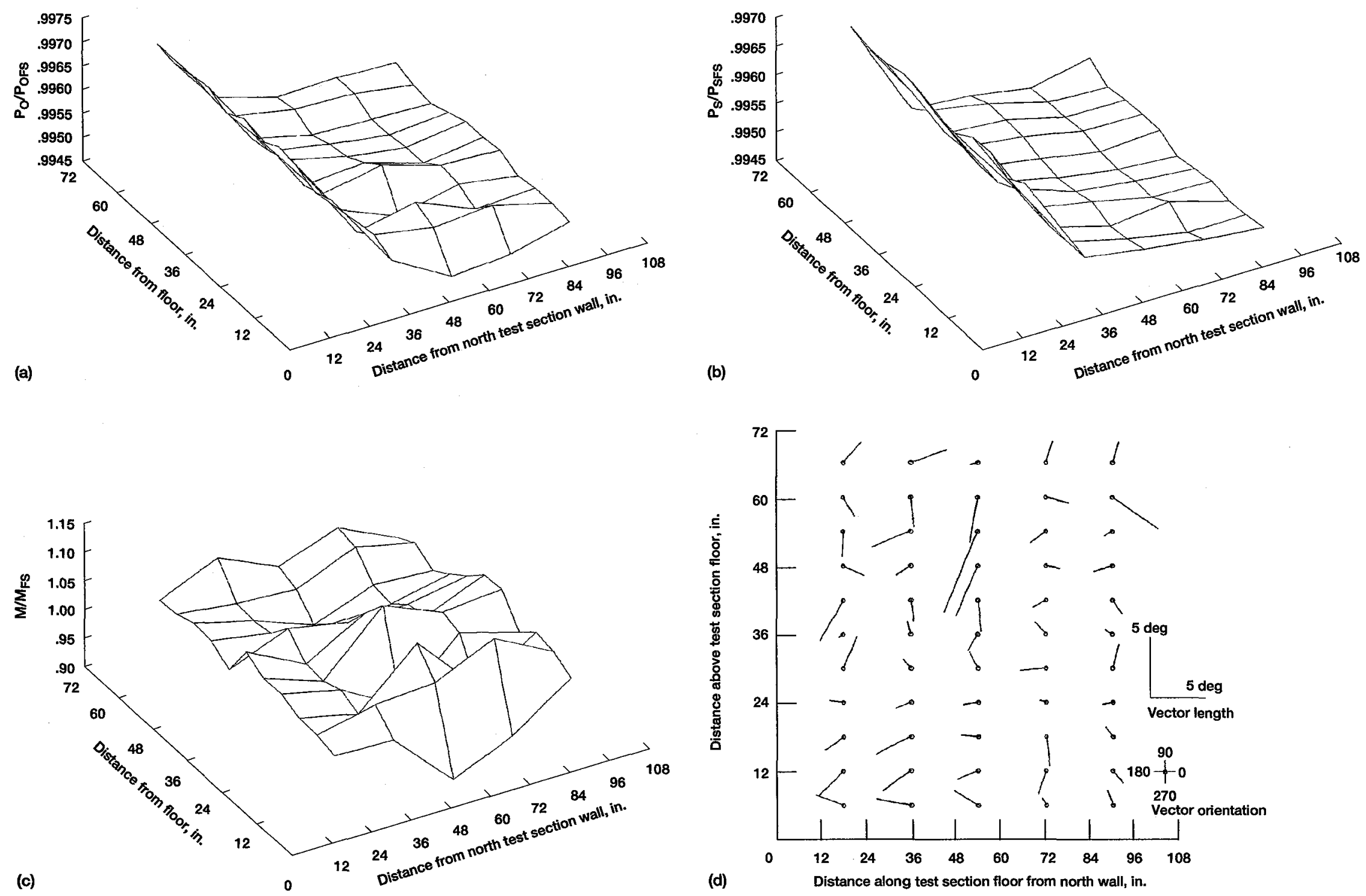

Figure 23.-Test section flow field survey data at exit survey station for a test section velocity of $\mathbf{5 0}$ mph. (a) Total pressure ratio. (b) Static pressure ratio. (c) Mach number ratio. (d) Flow angularity vectors. 

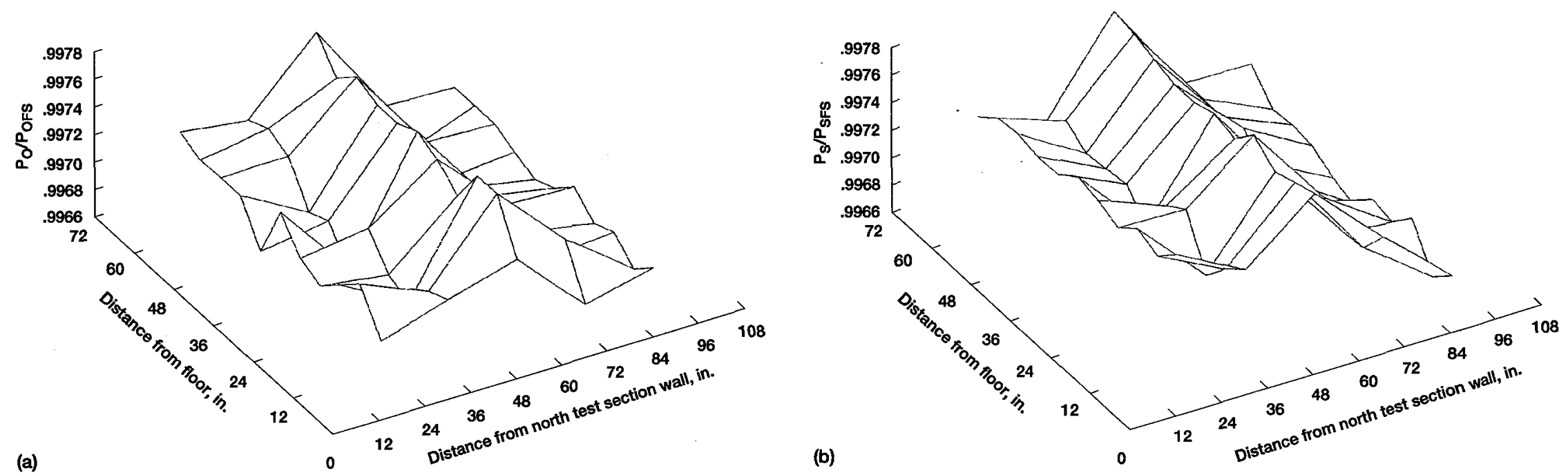

నั
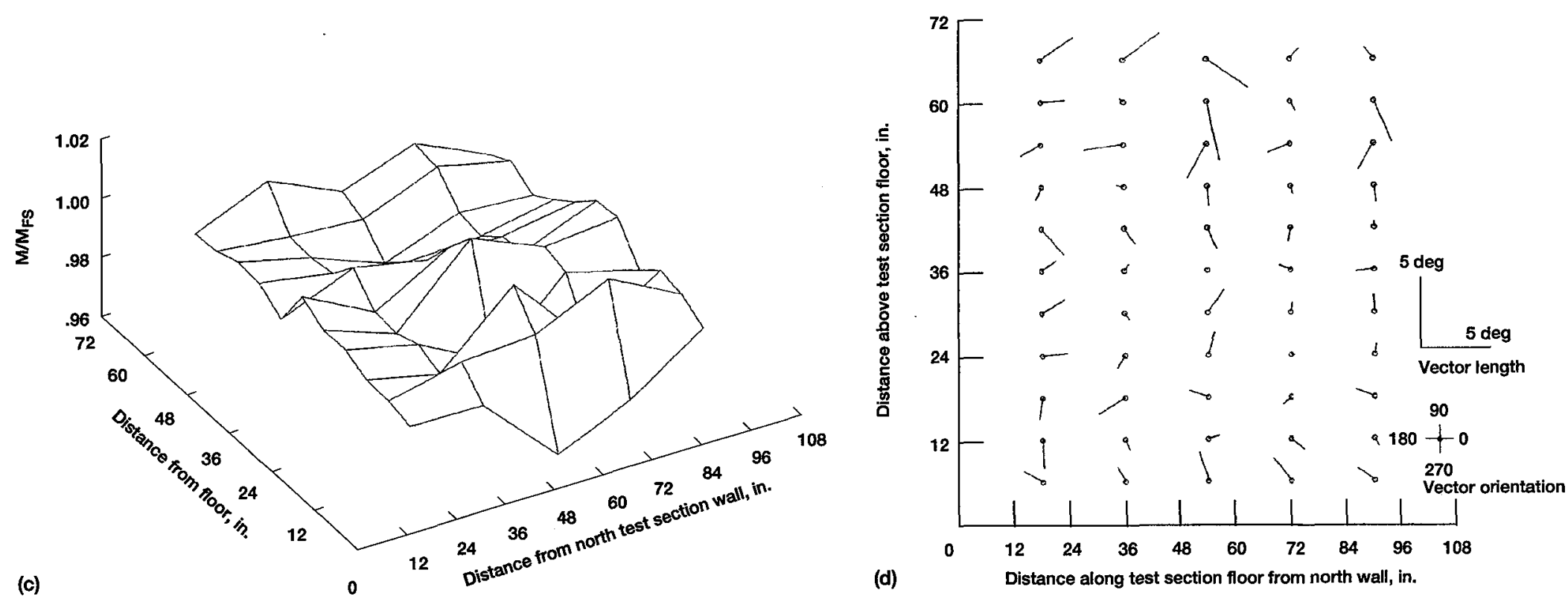

Figure 24.-Test section flow field survey data at inlet survey station for a test section velocity of $100 \mathrm{mph}$. (a) Total pressure ratio. (b) Static pressure ratio. (c) Mach number ratio. (d) Flow angularity vectors. 

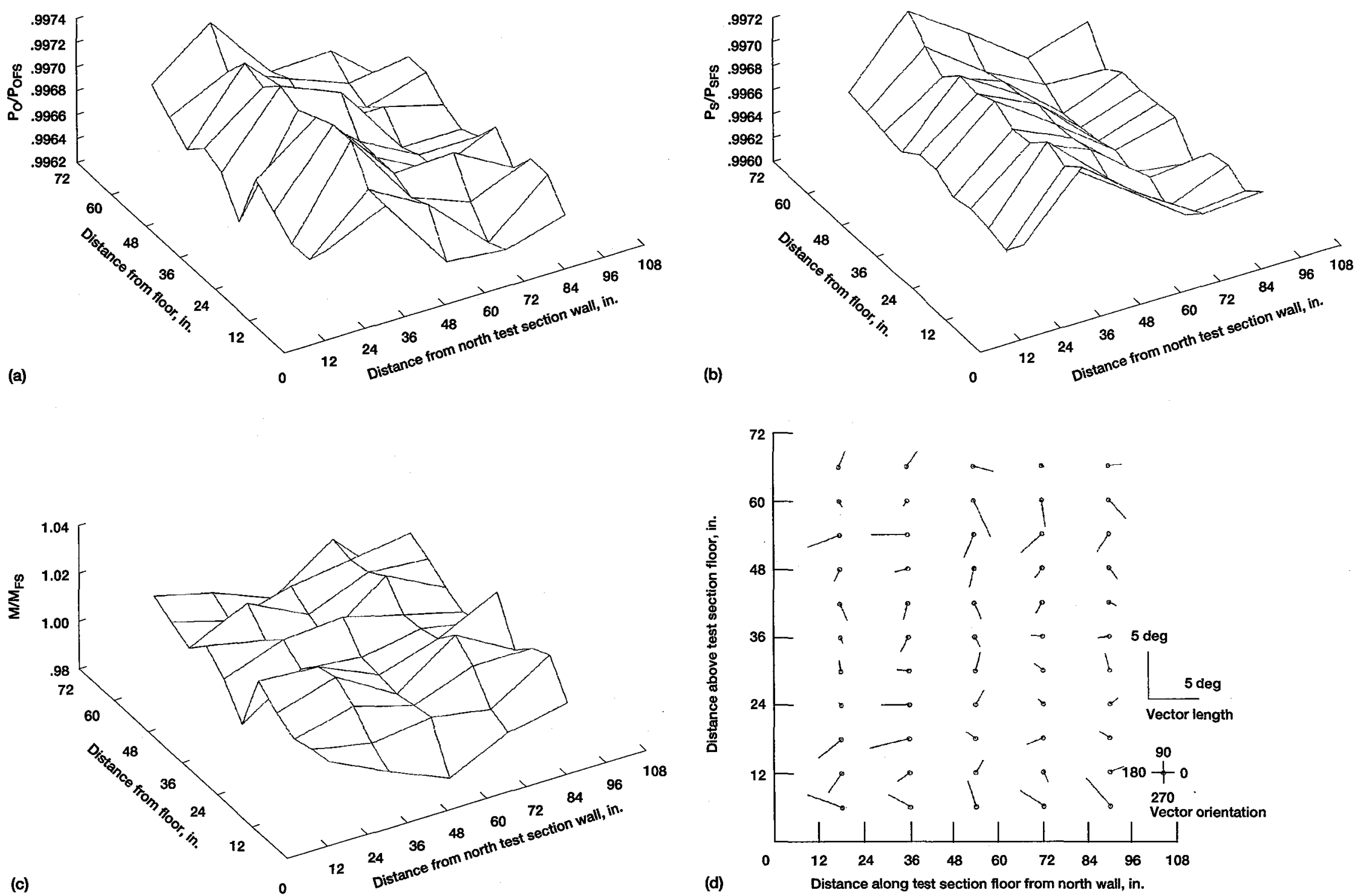

Figure 25.-Test section flow field survey data at test plane survey station for a test section velocity of $100 \mathrm{mph}$. (a) Total pressure ratio. (b) Static pressure ratio. (c) Mach number ratio. (d) Flow angularity vectors. 

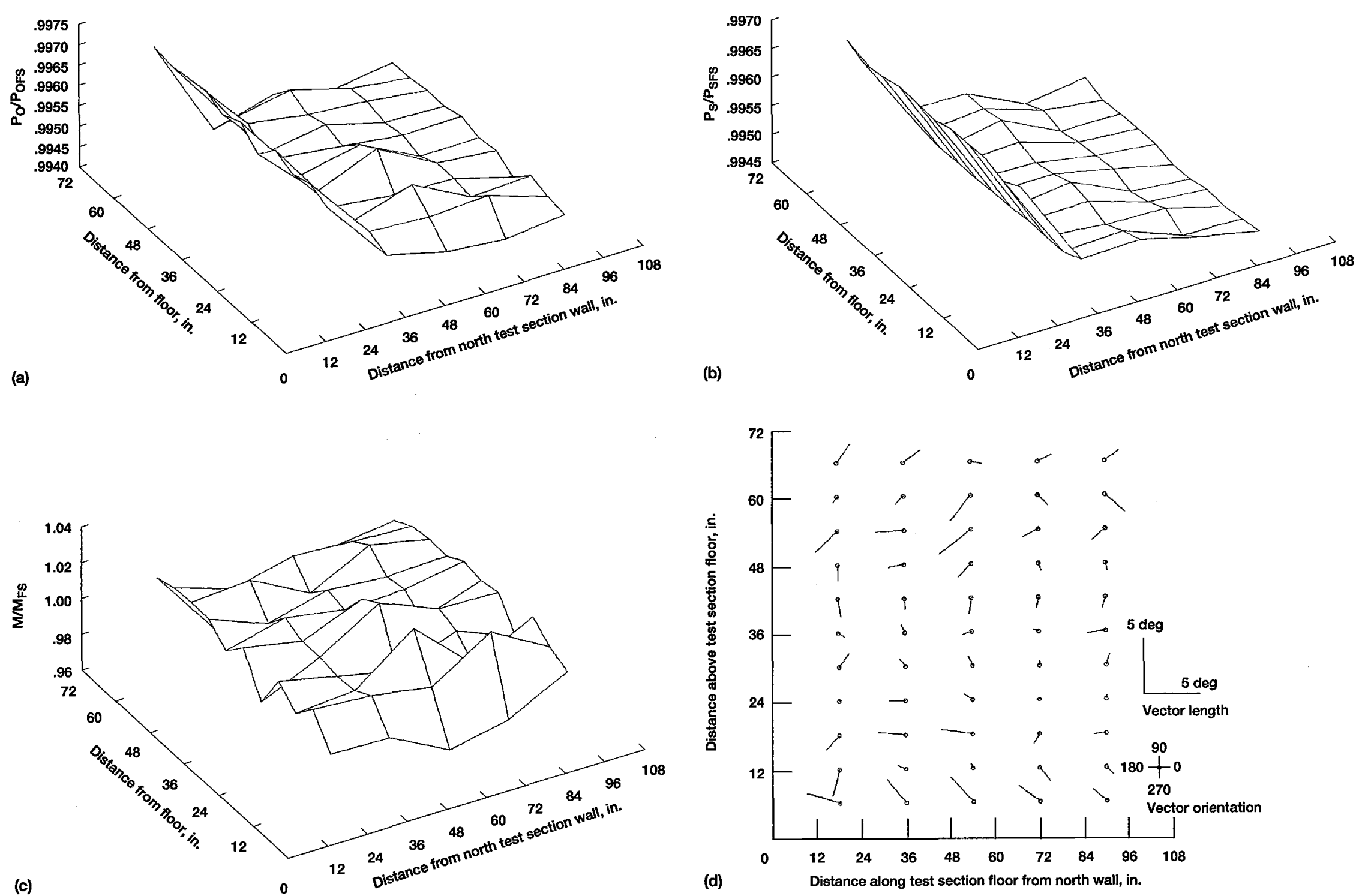

Figure 26.-Test section flow field survey data at exit survey station for a test section velocity of $100 \mathrm{mph}$. (a) Total pressure ratio. (b) Static pressure ratio. (c) Mach number ratio. (d) Flow angularity vectors. 

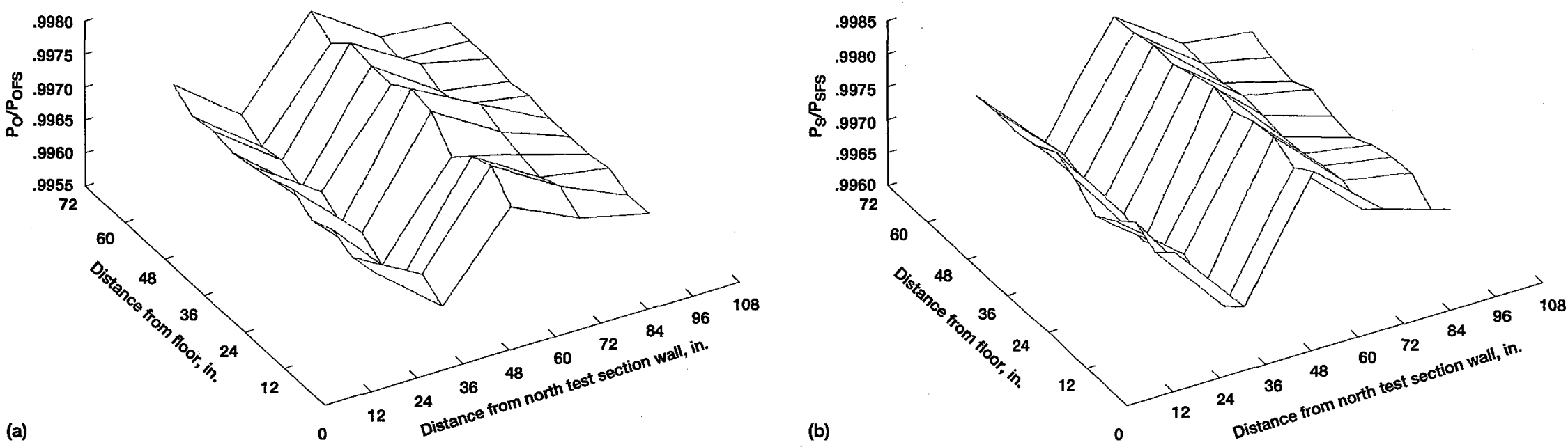

No
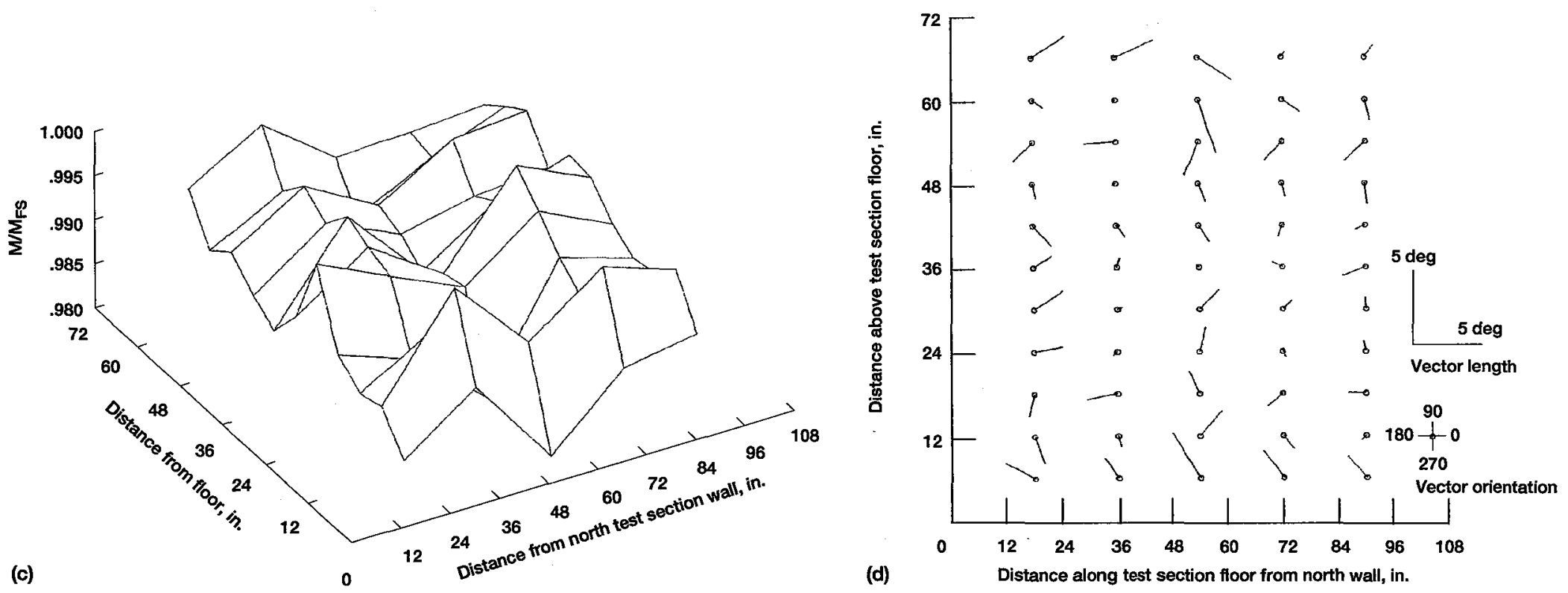

Figure 27.-Test section flow field survey data at inlet survey station for a test section velocity of $150 \mathrm{mph}$. (a) Total pressure ratio. (b) Static pressure ratio. (c) Mach number ratio. (d) Flow angularity vectors. 

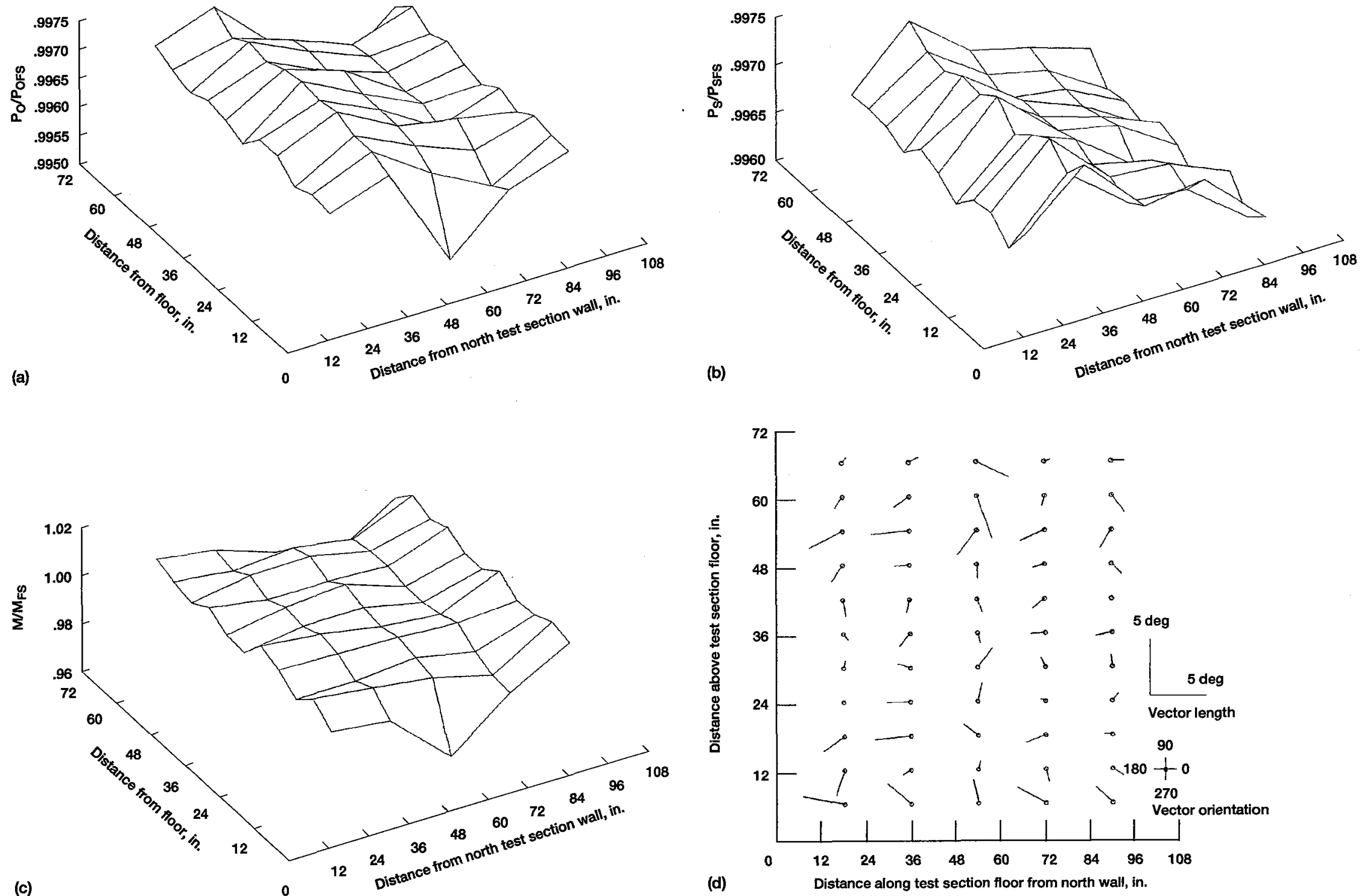

Figure 28.-Test section flow field survey data at test plane survey station for a test section velocity of 150 mph. (a) Total pressure ratio. (b) Static pressure ratio. (c) Mach number ratio. (d) Flow angularity vectors. 



Figure 29.-Test section flow field survey data at exit survey station for a test section velocity of $150 \mathrm{mph}$. (a) Total pressure ratio. (b) Static pressure ratio. (c) Mach number ratio. (d) Flow angularity vectors. 

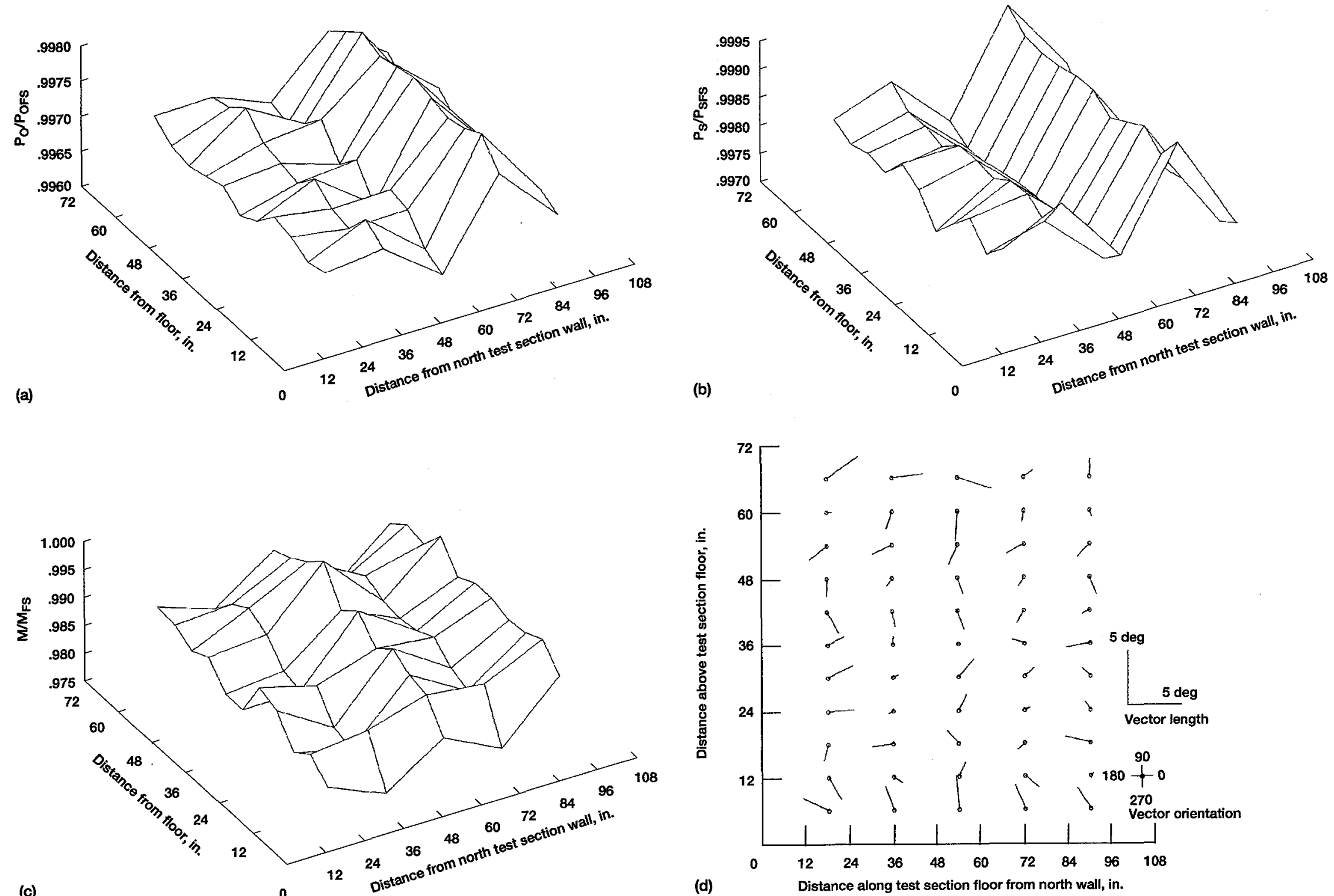

Figure 30.-Test section flow field survey data at inlet survey station for a test section velocity of $200 \mathrm{mph}$. (a) Total pressure ratio. (b) Static pressure ratio. (c) Mach number ratio. (d) Flow angularity vectors. 

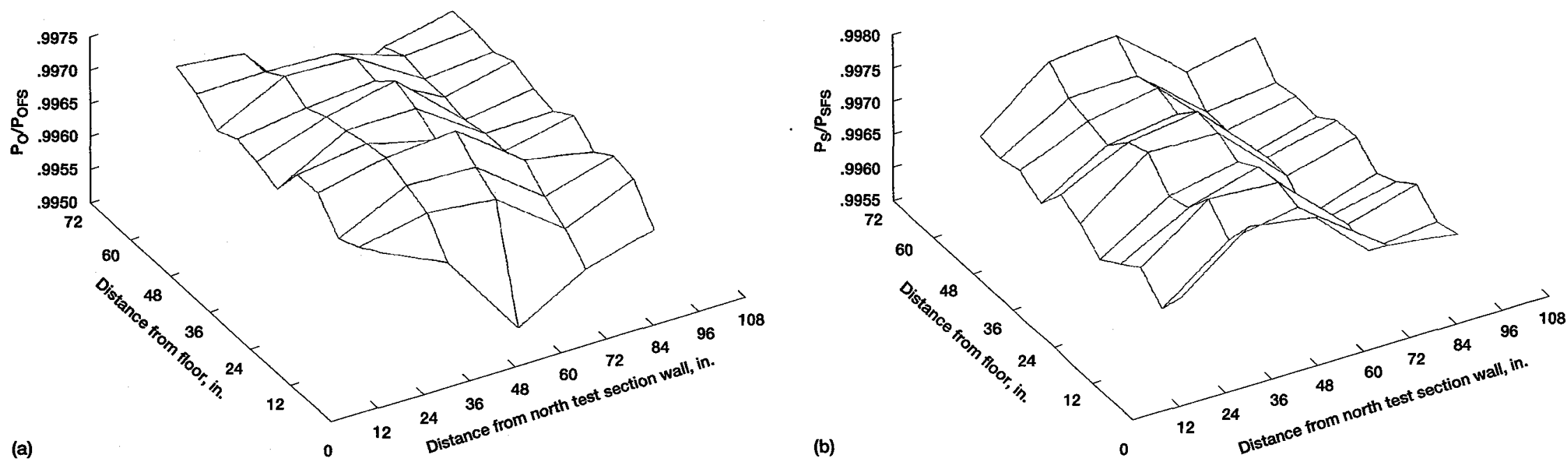

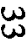
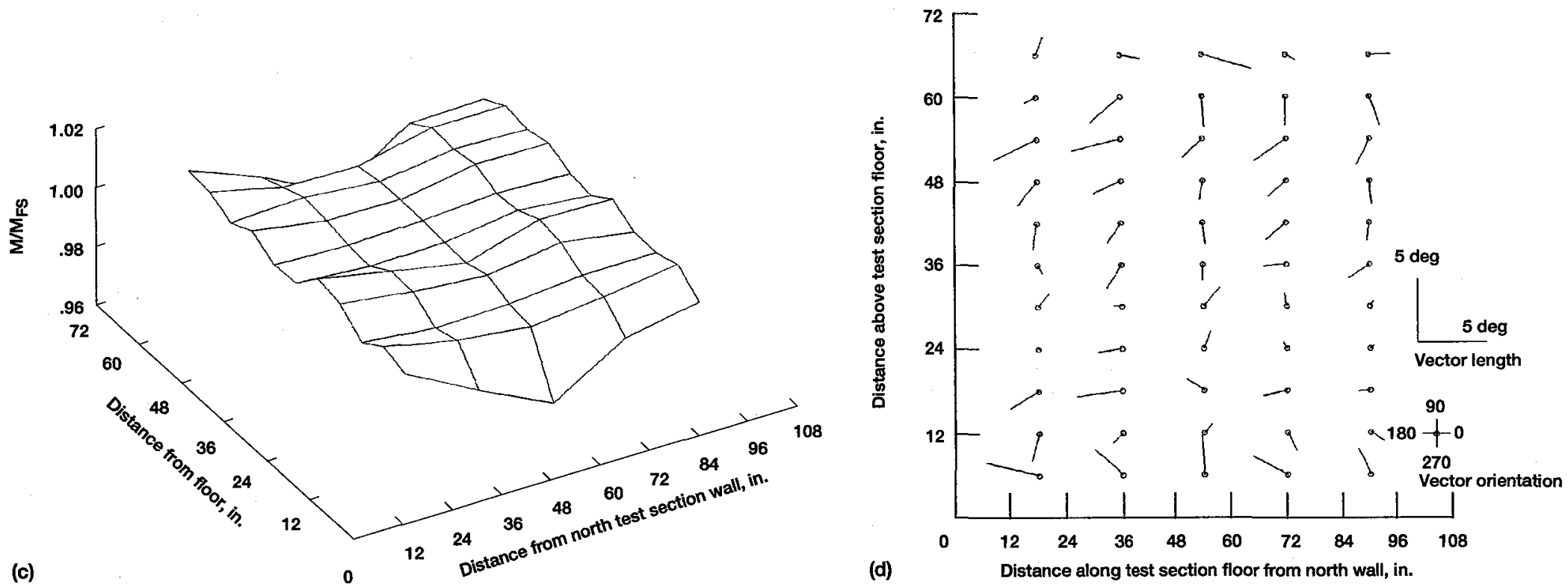

Figure 31.-Test section flow field survey data at test plane survey station for a test section velocity of $200 \mathrm{mph}$. (a) Total pressure ratio. (b) Static pressure ratio. (c) Mach number ratio. (d) Flow angularity vectors. 

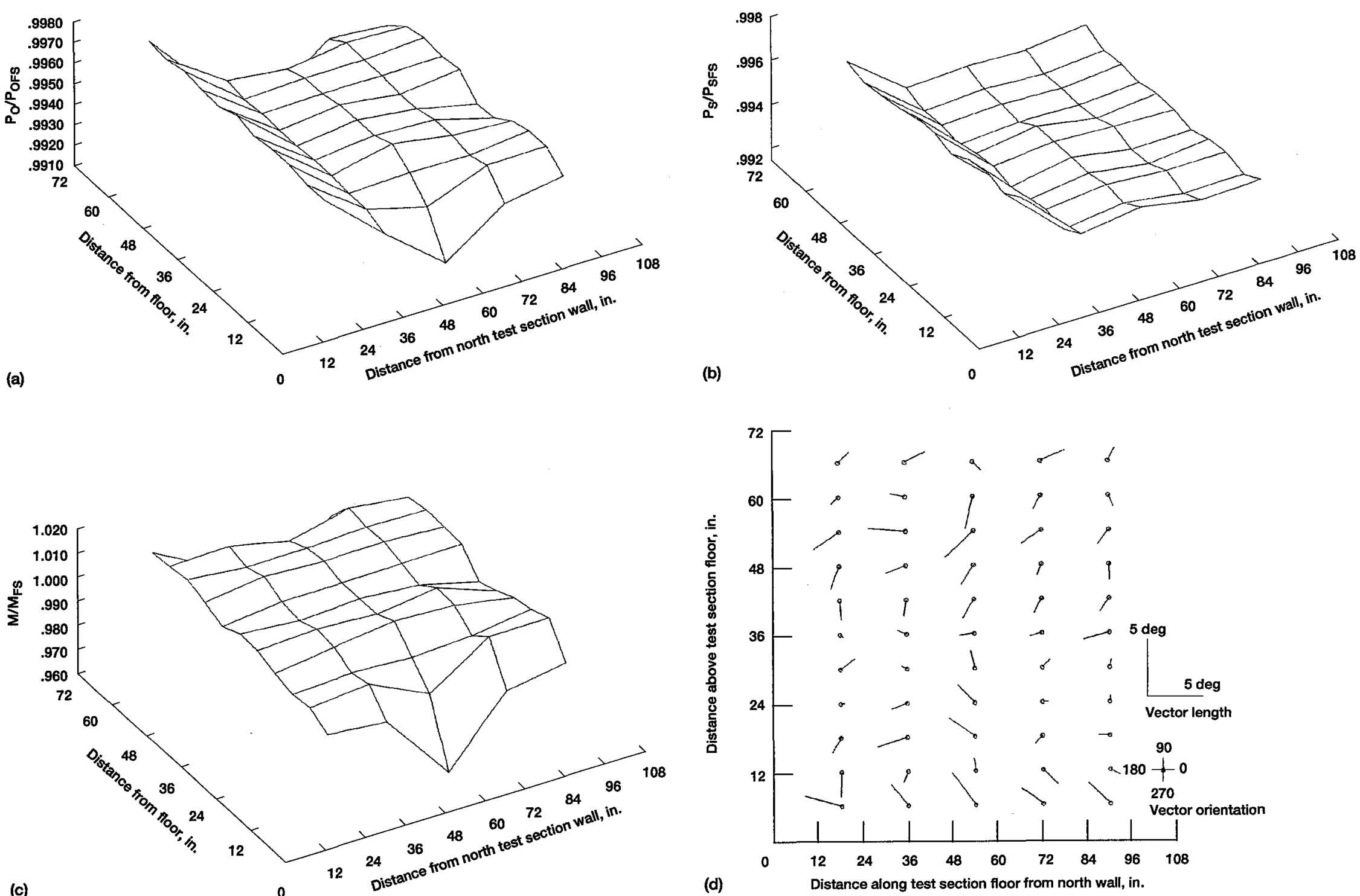

Figure 32.-Test section flow field survey data at exit survey station for a test section velocity of $\mathbf{2 0 0} \mathrm{mph}$. (a) Total pressure ratio. (b) Static pressure ratio. (c) Mach number ratio. (d) Flow angularity vectors. 

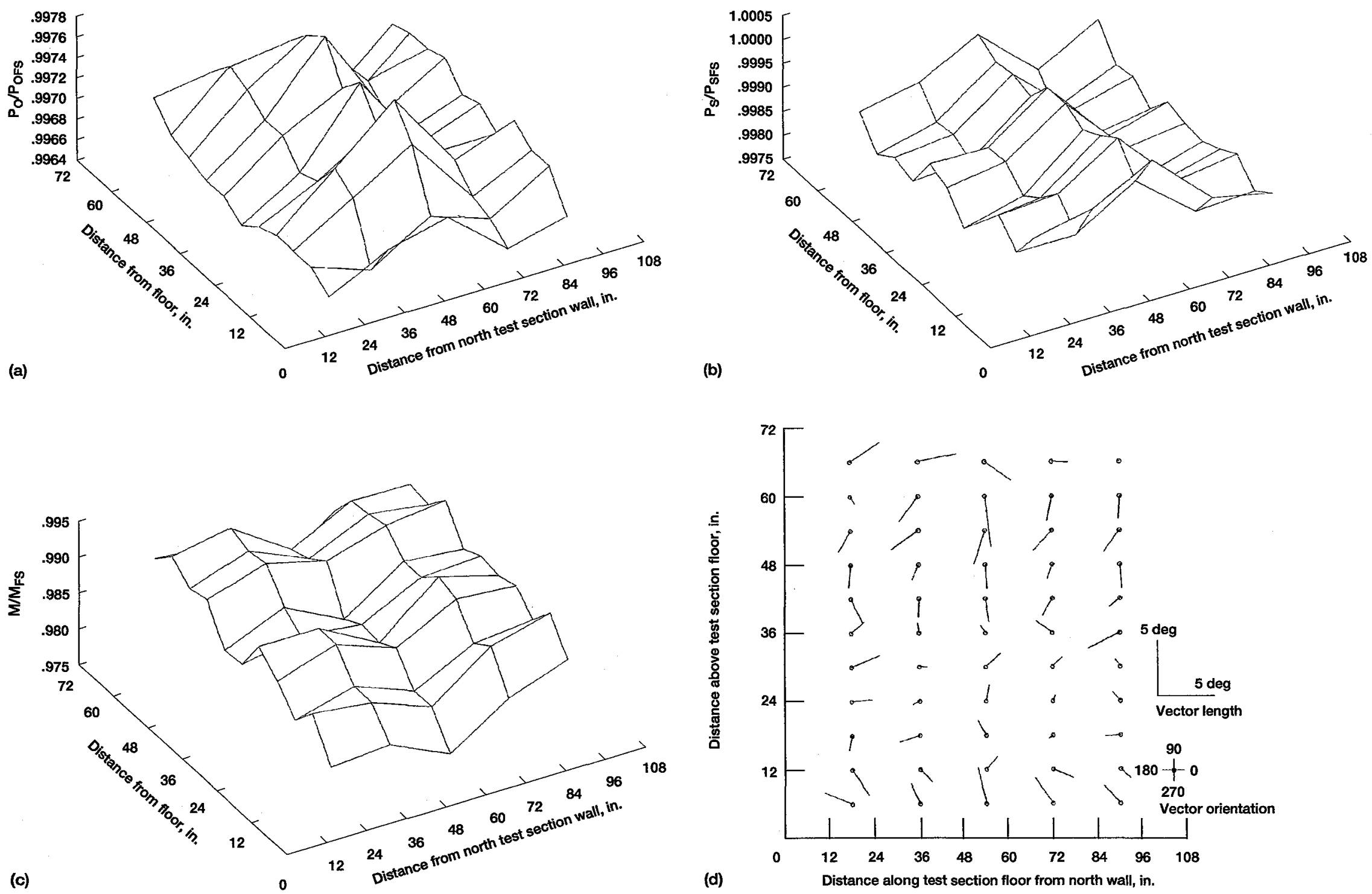

Figure 33.-Test section flow field survey data at inlet survey station for a test section velocity of $250 \mathrm{mph}$. (a) Total pressure ratio. (b) Static pressure ratio. (c) Mach number ratio. (d) Flow angularity vectors. 

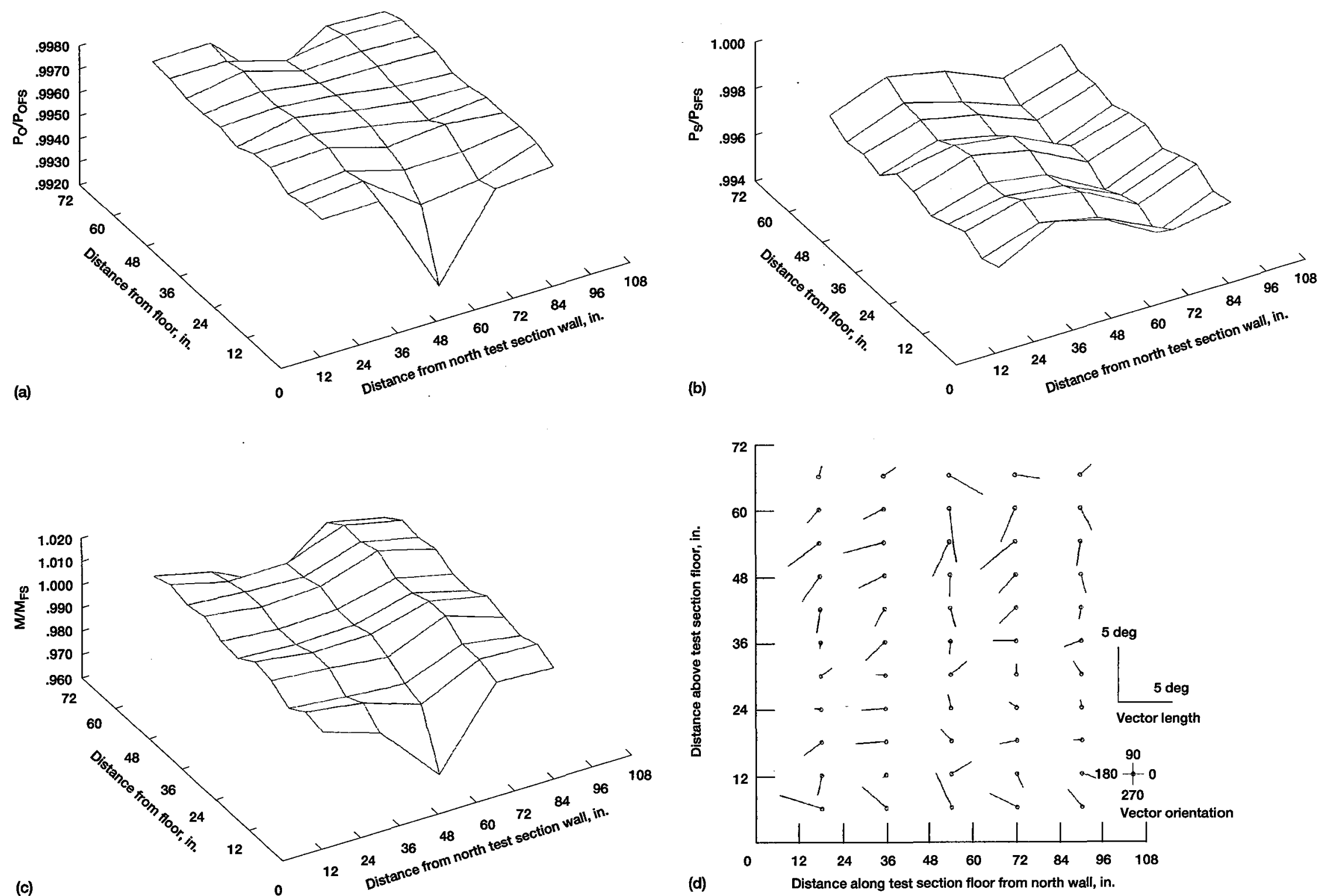

Figure 34.-Test section flow field survey data at test plane survey station for a test section velocity of $250 \mathrm{mph}$. (a) Total pressure ratio. (b) Static pressure ratio. (c) Mach number ratio. (d) Flow angularity vectors. 

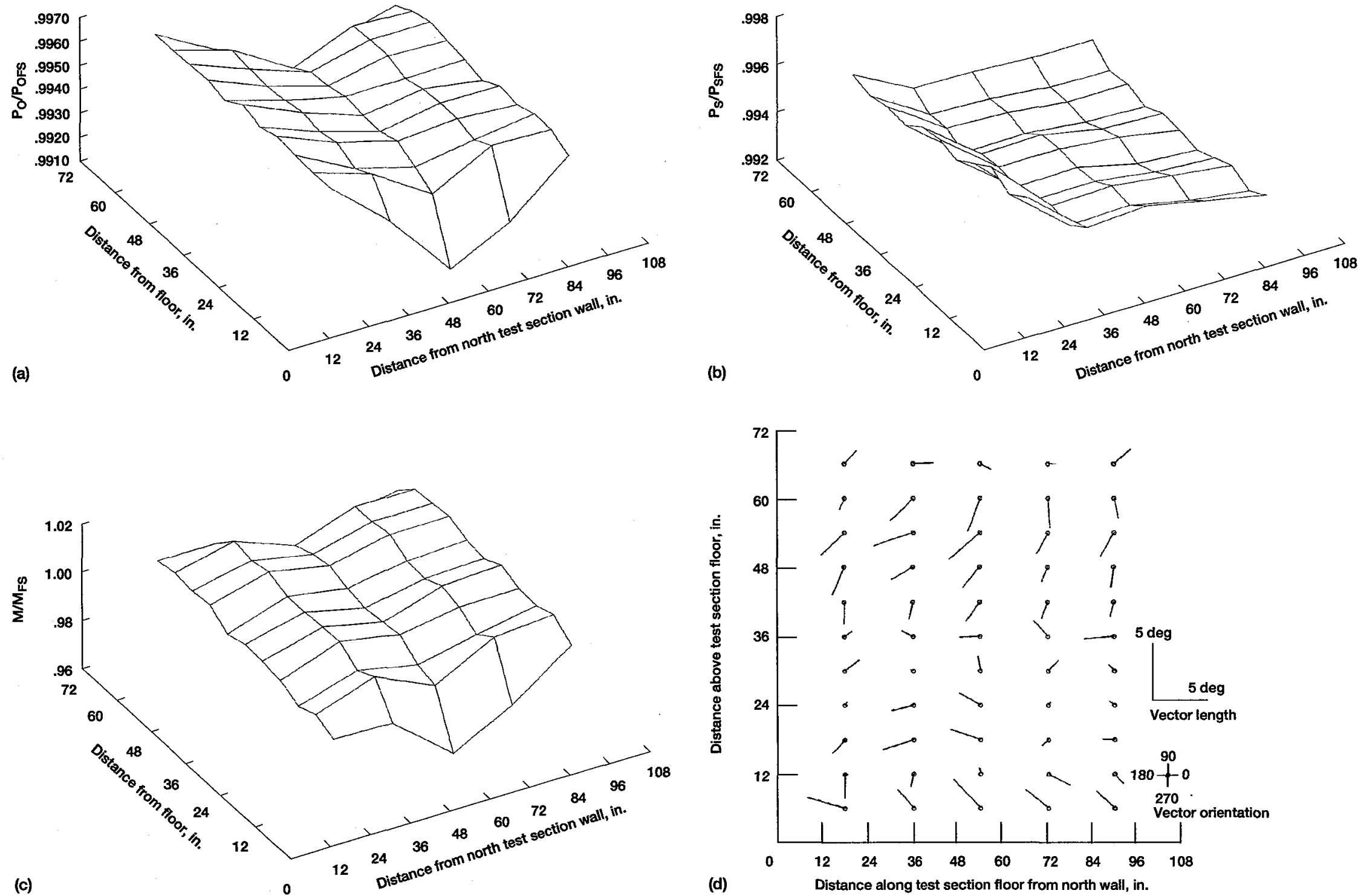

Figure 35.-Test section flow field survey data at exit survey station for a test section velocity of $250 \mathrm{mph}$. (a) Total pressure ratio. (b) Static pressure ratio. (c) Mach number ratio. (d) Flow angularity vectors. 

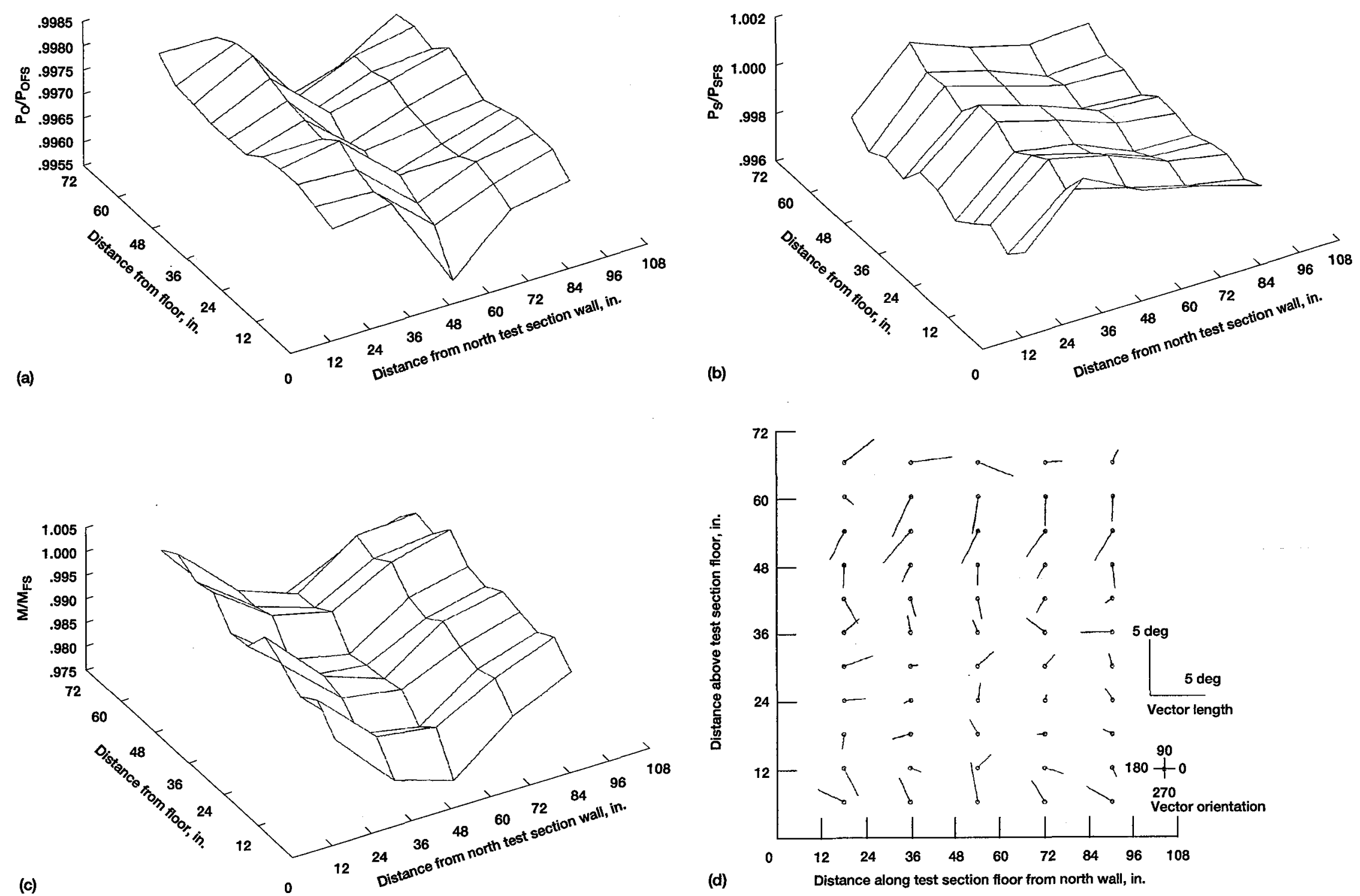

Figure 36.-Test section flow field survey data at inlet survey station for a test section velocity of $275 \mathrm{mph}$. (a) Total pressure ratio. (b) Static pressure ratio. (c) Mach number ratio. (d) Flow angularity vectors. 

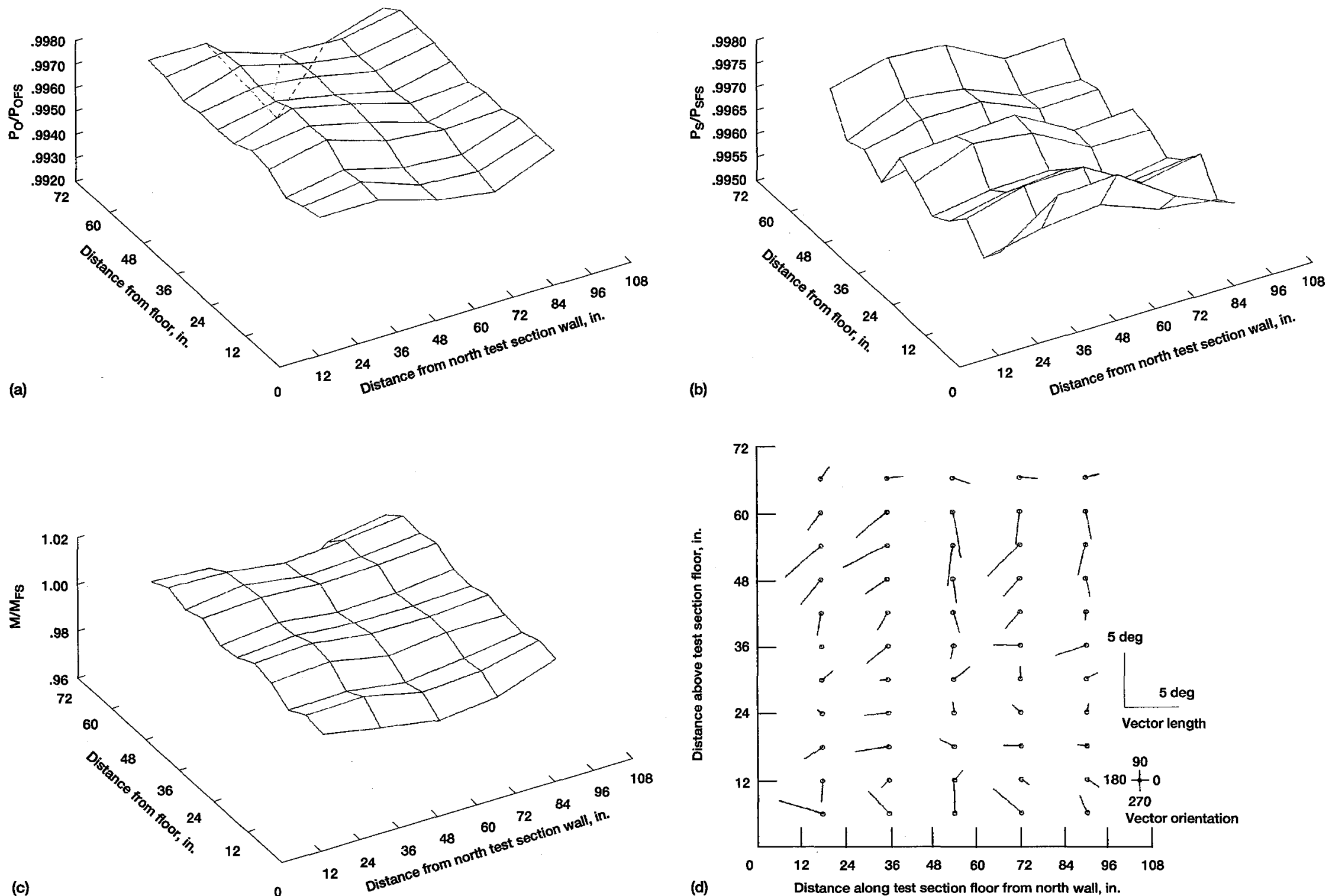

Figure 37.-Test section flow field survey data at test plane survey station for a test section velocity of $275 \mathrm{mph}$. (a) Total pressure ratio. (b) Static pressure ratio. (c) Mach number ratio. (d) Flow angularity vectors. 

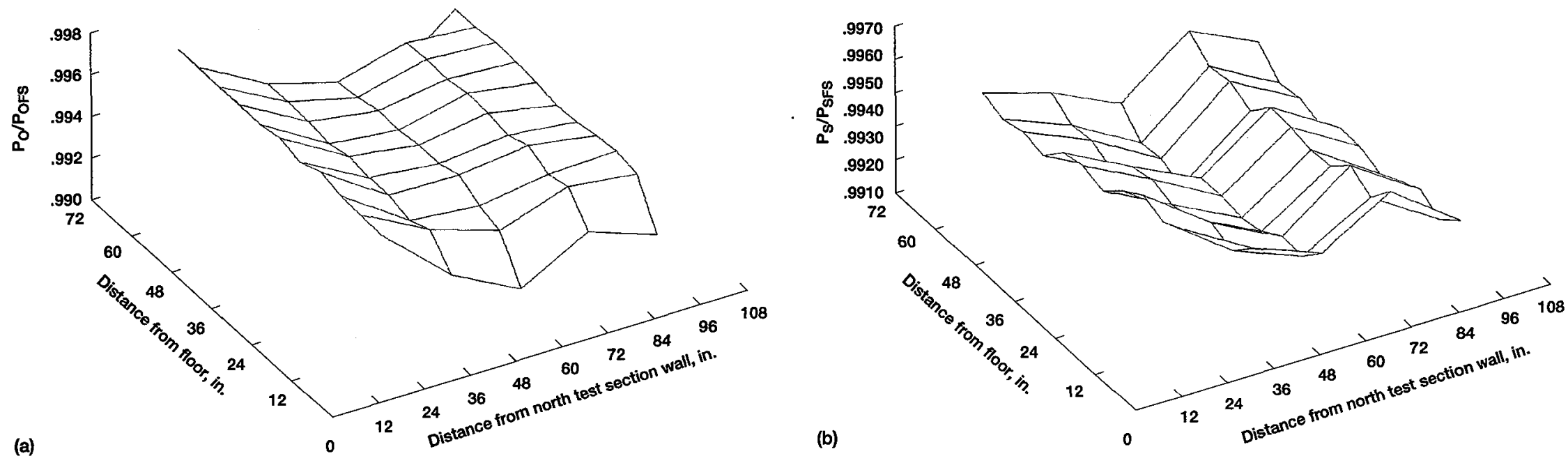

t
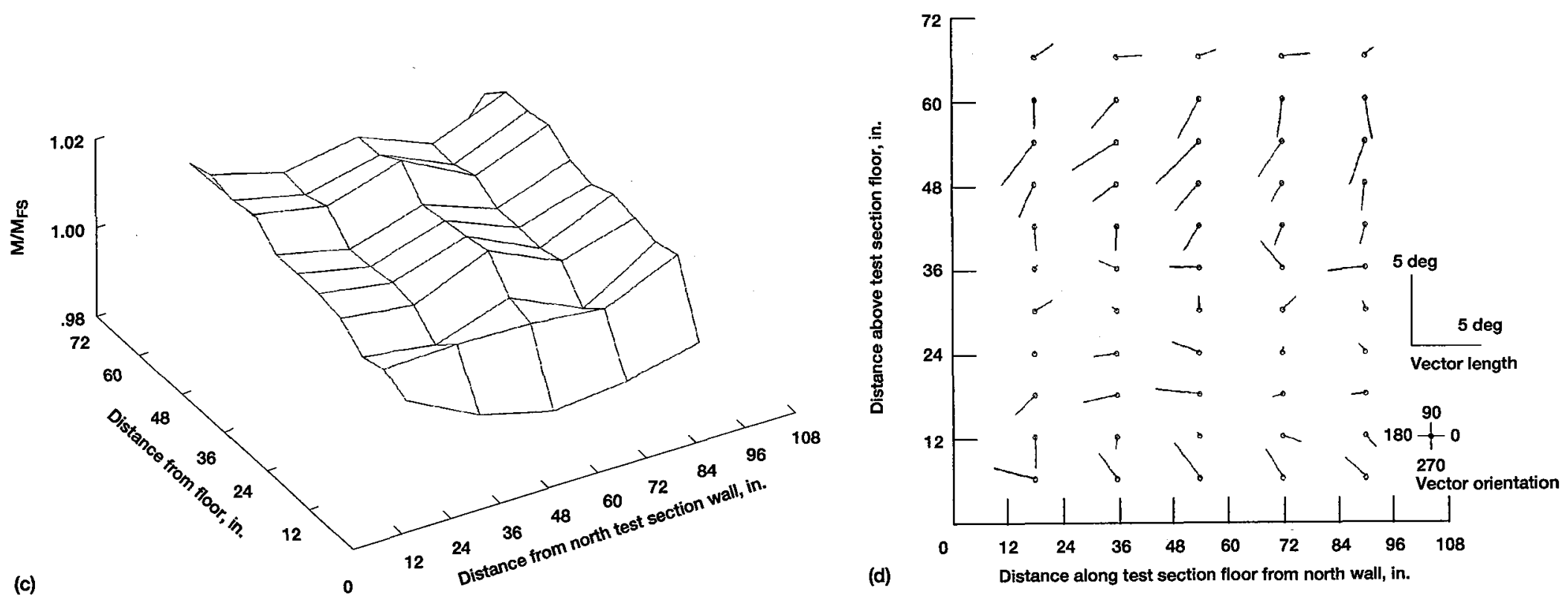

Figure 38.-Test section flow field survey data at exit survey station for a test section velocity of $275 \mathrm{mph}$. (a) Total pressure ratio. (b) Static pressure ratio. (c) Mach number ratio. (d) Flow angularity vectors. 

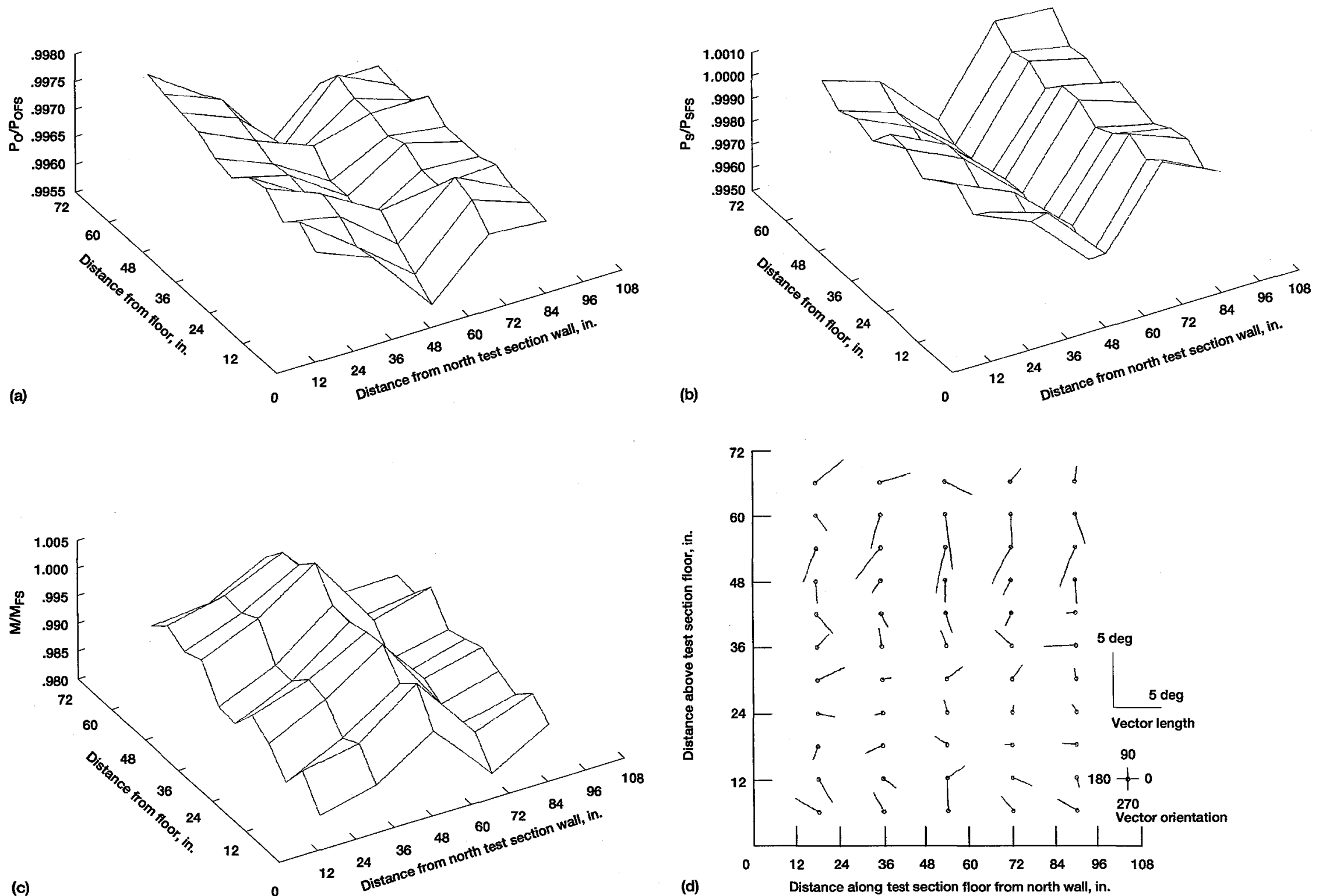

Figure 39.-Test section flow field survey data at inlet survey station for a test section velocity of $300 \mathrm{mph}$. (a) Total pressure ratio. (b) Static pressure ratio. (c) Mach number ratio. (d) Flow angularity vectors. 

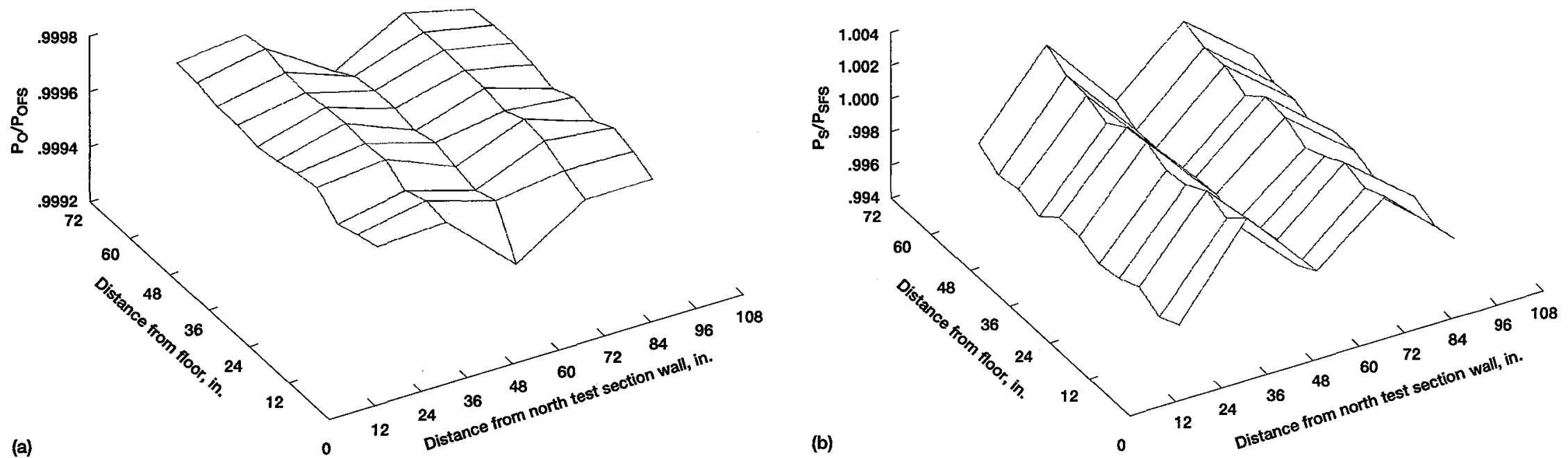

A
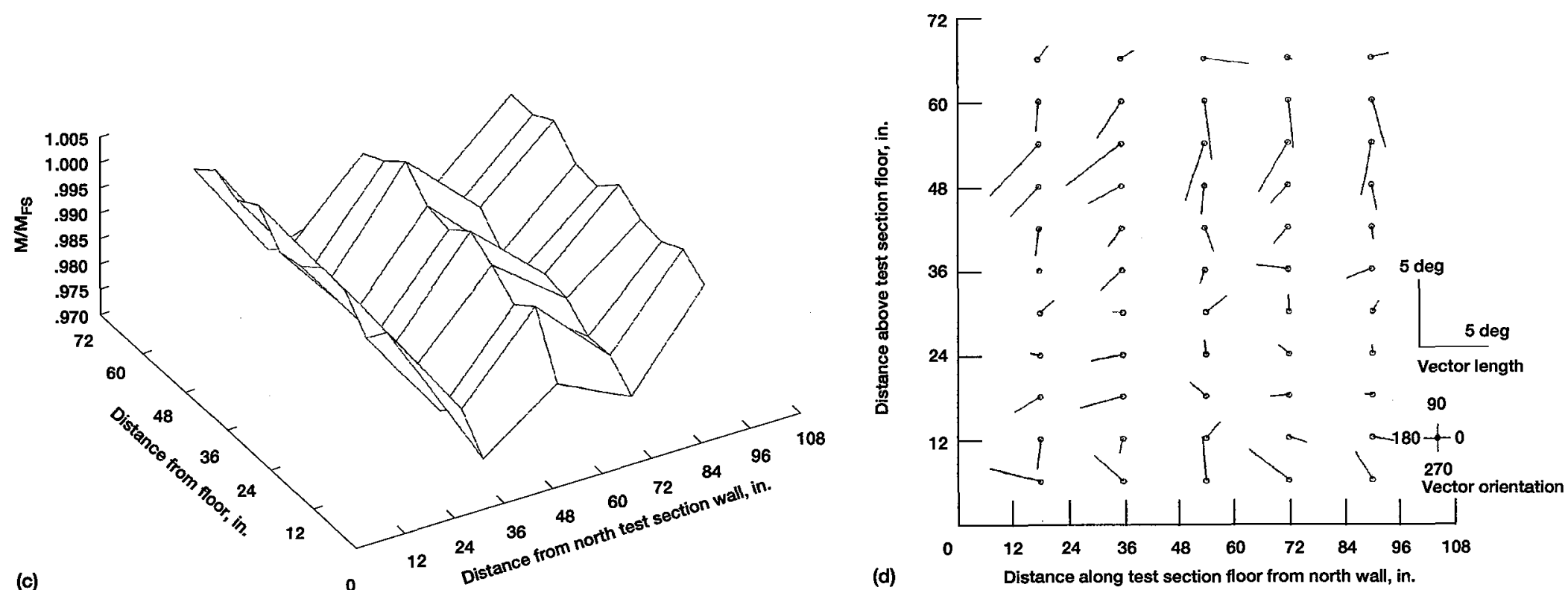

Figure 40.-Test section flow field survey data at test plane survey station for a test section velocity of $300 \mathrm{mph}$. (a) Total pressure ratio. (b) Static pressure ratio. (c) Mach number ratio. (d) Flow angularity vectors. 

Public reporting burden for this collection of information is estimated to average 1 hour per response, including the time for reviewing instructions, searching existing data sources, gathering and maintaining the data needed, and completing and reviewing the collection of information. Send comments regarding this burden estimate or any ofher aspect of this collection of information, including suggestions for reducing this burden, to Washington Headquarters Services, Directorate for Information Operations and Reports, 1215 Jefferson Davis Highway, Suite 1204, Artington, VA 22202-4302, and to the Office of Management and Budget, Paperwork Reduction Project (0704-0188), Washington, DC 20503.

\begin{tabular}{|l|l|l|}
\hline 1. AGENCY USE ONLY (Leave blank) & $\begin{array}{r}\text { 2. REPORT DATE } \\
\text { June } 1994\end{array}$ & $\begin{array}{r}\text { 3. REPORT TYPE AND DATES COVERED } \\
\text { Technical Memorandum }\end{array}$ \\
\hline
\end{tabular}

4. TITLE AND SUBTITLE

Flow Quality Studies of the NASA Lewis Research Center Icing Research Tunnel

6. AUTHOR(S)

E. Allen Arrington, Mark T. Pickett, and David W. Sheldon

7. PERFORMING ORGANIZATION NAME(S) AND ADDRESS(ES)

National Aeronautics and Space Administration

Lewis Research Center

Cleveland, Ohio 44135-3191

National Aeronautics and Space Administration

Washington, D.C. 20546-0001
10. SPONSORING/MONITORING AGENCY REPORT NUMBER

WU-505-62-84

8. PERFORMING ORGANIZATION REPORT NUMBER

NASA TM-106545

AIAA-94-2590

11. SUPPLEMENTARY NOTES

SUPPLEMENTARY NOTES
Prepared for the 18th Aerospace Ground Testing Conference sponsored by the American Institute of Aeronautics and Astronautics, Colorado Springs, Colorado, June 20-23, 1994. E. Allen Arrington, NYMA, Inc., Engineering Services Division, Brook Park, Ohio 44142 (work funded by NASA Contract NAS3-25266 with Sverdrup Technology, Inc., Lewis Research Center Group), and Mark T. Pickett and David W. Sheldon, NASA Lewis Research Center. Responsible person, Mark T. Pickett, organization code 2830, (216) 433-5721.

12a. DISTRIBUTION/AVAILABILITY STATEMENT

12b. DISTRIBUTION CODE

Unclassified - Unlimited

Subject Category 09

13. ABSTRACT (Maximum 200 words)

A series of studies have been conducted to determine the flow quality in the NASA Lewis Icing Research Tunnel. The primary purpose of these studies was to document airflow characteristics, including flow angularity, in the test section and tunnel loop. A vertically mounted rake was used to survey total and static pressure and two components of flow angle at three axial stations within the test section (test section inlet, test plane, and test section exit; 15 survey stations total). This information will be used to develop methods of improving the aerodynamic and icing characteristics within the test section. The data from surveys made in the tunnel loop were used to determine areas where overall tunnel flow quality and efficiency can be improved. A separate report documents similar flow quality surveys conducted in the diffuser section of the Icing Research Tunnel. The flow quality studies were conducted at several locations around the tunnel loop. Pressure, velocity, and flow angularity measurements were made by using both fixed and translating probes. Although surveys were made throughout the tunnel loop, emphasis was placed on the test section and tunnel areas directly upstream of the test section (settling chamber, bellmouth, and cooler). Flow visualization, by video recording smoke and tuft patterns, was also used during these studies. A great deal of flow visualization work was conducted in the area of the drive fan. Information gathered there will be used to improve the flow quality upstream and downstream of the fan.

14. SUBJECT TERMS

Wind tunnel; Flow quality; Flow field measurement

15. NUMBER OF PAGES 44

16. PRICE CODE

$\mathrm{A03}$

\begin{tabular}{|c|c|c|}
\hline $\begin{array}{c}\text { 17. SECURITY CLASSIFICATION } \\
\text { OF REPORT } \\
\text { Unclassified }\end{array}$ & $\begin{array}{c}\text { 18. SECURITY CLASSIFICATION } \\
\text { OF THIS PAGE } \\
\text { Unclassified }\end{array}$ & $\begin{array}{c}\text { 19. SECURITY CLASSIFICATION } \\
\text { OF ABSTRACT } \\
\text { Unclassified }\end{array}$ \\
\hline
\end{tabular}

NSN 7540-01-280-5500 